\title{
Article \\ Somatic Hypomethylation of Pericentromeric SST1 Repeats and Tetraploidization in Human Colorectal Cancer Cells
}

\author{
Beatriz González ${ }^{1,+} \oplus$, Maria Navarro-Jiménez ${ }^{1,+}{ }^{\oplus}$, María José Alonso-De Gennaro ${ }^{1} \mathbb{C}$, Sanne Marcia Jansen ${ }^{1}$, \\ Isabel Granada $^{2}(\mathbb{D})$, Manuel Perucho ${ }^{3}$ (D) and Sergio Alonso ${ }^{1, *(D)}$ \\ 1 Program of Predictive and Personalized Medicine of Cancer, Germans Trias i Pujol Research \\ Institute (PMPPC-IGTP), 08916 Badalona, Spain; bgonzalez@igtp.cat (B.G.); mnavarroj@igtp.cat (M.N.-J.); \\ majosealonso97@gmail.com (M.J.A.-D.G.); sannemjansen@gmail.com (S.M.J.) \\ 2 Cytogenetics Platform, Hematology Laboratory Service, Institut Català d'Oncologia, Hospital Germans Trias i \\ Pujol, Josep Carreras Leukaemia Research Institute, 08916 Badalona, Spain; igranada@iconcologia.net \\ 3 Sanford Burnham Prebys Medical Discovery Institute (SBP), La Jolla, CA 92037, USA; \\ mperucho@sbpdiscovery.org \\ * Correspondence: salonsou@igtp.cat \\ + B.G and M.N.-J. share equal contribution in this work.
}

check for updates

Citation: González, B.;

Navarro-Jiménez, M.; Alonso-De

Gennaro, M.J.; Jansen, S.M.; Granada,

I.; Perucho, M.; Alonso, S. Somatic

Hypomethylation of Pericentromeric SST1 Repeats and Tetraploidization in Human Colorectal Cancer Cells. Cancers 2021, 13, 5353. https:// doi.org/10.3390/cancers13215353

Academic Editor: Masahito Shimizu

Received: 2 August 2021

Accepted: 21 October 2021

Published: 26 October 2021

Publisher's Note: MDPI stays neutral with regard to jurisdictional claims in published maps and institutional affiliations.

Copyright: (c) 2021 by the authors. Licensee MDPI, Basel, Switzerland. This article is an open access article distributed under the terms and conditions of the Creative Commons Attribution (CC BY) license (https:/ / creativecommons.org/licenses/by/ $4.0 /)$.
Simple Summary: Cancer cells frequently exhibit an abnormal number of chromosomes, termed aneuploidy, often preceded by an aberrant genome duplication resulting in cells with double the number of chromosomes (tetraploidy). The cause of the aberrant genome-doubling remains unknown. Loss of DNA methylation is also frequent in cancer cells and has been found to be associated with aneuploidy. The mechanisms linking these alterations remain unclear. In this report, we describe the association between loss of methylation in a family of pericentromeric DNA sequences and sporadic genome-doubling in colorectal cancer cells cultured in vitro. These sequences are also hypomethylated in primary colorectal tumors, associated with inactivating mutations on genes of the main pathway controlling proper genome duplication. Our data suggest that the demethylation of these sequences might be associated with genome-doubling as early events in a subset of colorectal cancers, providing novel clues on the link between genome demethylation and aneuploidy in cancer.

Abstract: Somatic DNA hypomethylation and aneuploidy are hallmarks of cancer, and there is evidence for a causal relationship between them in knockout mice but not in human cancer. The non-mobile pericentromeric repetitive elements SST1 are hypomethylated in about $17 \%$ of human colorectal cancers (CRC) with some 5-7\% exhibiting strong age-independent demethylation. We studied the frequency of genome doubling, a common event in solid tumors linked to aneuploidy, in randomly selected single cell clones of near-diploid LS174T human CRC cells differing in their level of SST1 demethylation. Near-diploid LS174T cells underwent frequent genome-doubling events generating near-tetraploid clones with lower levels of SST1 methylation. In primary CRC, strong SST1 hypomethylation was significantly associated with global genomic hypomethylation and mutations in TP53. This work uncovers the association of the naturally occurring demethylation of the SST1 pericentromeric repeat with the onset of spontaneous tetraploidization in human CRC cells in culture and with TP53 mutations in primary CRCs. Altogether, our findings provide further support for an oncogenic pathway linking somatic hypomethylation and genetic copy number alterations in a subset of human CRC.

Keywords: genomic DNA hypomethylation; colorectal cancer; tetraploidization; chromosome instability; repetitive elements; polyploidy 


\section{Introduction}

\subsection{DNA Methylation Alterations in Cancer}

DNA methylation is essential for the establishment and maintenance of cell-typespecific transcriptional profiles during cell differentiation, conferring cell type identity. It is also involved in suppressing the potentially harmful mobilization of endogenous transposable elements [1,2]. In humans, DNA methylation takes place almost exclusively in the cytosine residues within CpG dinucleotides. In differentiated somatic cells, most (70-90\%) CpG sites are methylated, depending on the cell type [3,4]. DNA methylation is a dynamic process mediated by the activity of DNA methyltransferases and TET enzymes that are involved in the deposition and removal of DNA methylation, respectively [5]. During the lifespan of an individual, the level of genomic methylation in normal tissues declines at a rate proportional to their proliferative potential [6-8]. Notably, while the overall level of methylation declines with aging, some loci become more methylated [9]. In addition, environmental factors (exposure to pollutants, tobacco smoking, nutritional factors, among others) as well as the microbiota have been associated with global or site-specific DNA methylation alterations $[10,11]$.

DNA methylation alterations are a common feature of cancer cells, with both gains and losses of methylation at different loci, associated with changes in chromatin structure and aberrant gene transcriptional activity at those locations [12]. The gain of methylation (hypermethylation), particularly on gene-promoter-associated CpG islands, is generally associated with a more compact chromatin conformation and transcriptional silencing, while the loss of methylation (hypomethylation) is generally associated with an open chromatin conformation and transcriptional activation of the neighboring genes [13,14]. The effect of DNA methylation alterations, however, is not limited to just the neighboring genes. Transcriptional dysregulation spanning large chromosomal regions $(>1 \mathrm{Mb})$ containing both DNA-methylated and neighboring unmethylated genes that became coordinately suppressed by global changes in histone modification has been described in colorectal cancer (CRC) $[15,16]$ and other solid tumors ([17] and references therein). The opposite phenomenon, i.e., regions with long range epigenetic activation, has also been reported [18]. Moreover, much of the methylation change in cancer involves regions exhibiting coordinated focal hypermethylation concentrated within regions of long-range $(>100 \mathrm{~kb})$ hypomethylation that are associated with late-replication domains of the genome, indicating a link between genome duplication and DNA methylation alterations [19-21]. Coordinated DNA methylation changes are not exclusively in cis genes but also occur in genes located in different chromosomes. One of the most widely studied examples is the coordinated $\mathrm{CpG}$ island promoter hypermethylation, referred to as the $\mathrm{CpG}$ island methylator phenotype (CIMP), first identified in CRC [22]. CIMP is associated with proximal CRCs with BRAF V600E mutation and microsatellite instability (MSI) caused by the hypermethyaltion of $h M L H 1$. The underlying reason for the BRAF-CIMP-MSI association was found to be the RAF-MEK-ERK-induced phosphorylation of MAGF, a transcriptional repressor that upon phosphorylation binds the promoters of $h M L H 1$ and other CIMP genes and recruits a set of corepressors that includes the DNA methyltransferase DNMT3B, resulting in hypermethylation and transcriptional silencing [23]. This pathway is also involved in aberrant gene-promoter hypermethylation in mutant-BRAF melanomas [24]. The coordinated epigenetic silencing of tumor suppressor genes can be also mediated by KRAS oncogenic activation through a pathway involving the upregulation of ZNF304, a DNA-binding protein that recruits a corepressor complex that includes the DNA methyltransferase DNMT1 [25]. All these findings highlight the complexity of the mechanisms underlying the aberrant DNA methylation in cancer, including 3D genomic organization, altered signaling pathways, environmental factors and cell-cycle-associated alterations.

The genome-wide hypomethylation typically found in cancers [13] mainly reflects the loss of methylation of interspersed repetitive DNA elements that account for up $45 \%$ of our genome and over $90 \%$ of the methylated CpG sites [26-28]. Among these, LINE-1 elements have been widely employed as surrogate markers of global DNA methylation 
due to their high CpG content and abundance [29,30]. Genome-wide hypomethylation is associated with copy number alterations in human cancers [31,32] and leads to tumor formation in mice with knocked out methyltransferases, accompanied by chromosomal instability [33]. We previously found that global hypomethylation in gastric and colorectal cancers increased with patient age and correlated with genomic damage [34]. Based on these findings, a "wear and tear" model, linking aging to cancer development, was proposed. It postulated that changes in methylation-particularly hypomethylation-occur in normal stem cells or their descendants during aging because of the inevitable accumulation of errors during genome replication. When a minimum tolerable demethylation level is reached, or some particular sequences are affected, proper mitosis would be compromised, leading to chromosomal missegregation, transcriptional dysregulation and putatively contributing to oncogenesis [34].

\subsection{Hypomethylation of SST1 Pericentromeric Repeats in Cancer}

One of the loci that we found frequently hypomethylated in gastrointestinal tumors corresponded to pericentromeric repeated elements SST1 [34,35], also known as NBL2. These sequences were previously found to undergo hypomethylation in neuroblastoma [36] and methylation changes (both hypomethylation and hypermethylation) in different types of cancer [37]. SST1 sequences are also hypomethylated in cells from patients with immunodeficiency, centromeric region instability, facial anomalies syndrome (ICF) [38], associated with mutations in the DNMT3B DNA methyltransferase gene [39,40].

SST1 elements are 1.4kb long sequences moderately repeated in tandem clusters [41], mainly located near the centromeres of the short arm of acrocentric chromosomes 13, 14, 15 and 21. We identified that these sequences were mostly methylated in normal colonic mucosa samples, exhibiting an average of $88.7 \% \pm 9.0 \%$ methylation in their CpGrich $317 \mathrm{bp}$ internal region. Around $22 \%$ of the CRCs were hypomethylated ( $>5 \%$ lower methylation compared with matched normal tissue), including 7\% of CRCs that exhibited strong hypomethylation of SST1 elements $(\geq 10 \%$ demethylation compared with matched normal tissue), which we named "severe" hypomethylation. The majority of the CRCs $(78 \%)$ exhibited no hypomethylation, with a few of them (around $5 \%$ ) exhibiting moderate hypermethylation ( $>5 \%$ hypermethylation compared to matched normal tissue). Notably, no association between SST1 hypomethylation and patient age was found, and, in fact, strong hypomethylation ( $\geq 10 \%$ decrease in methylation) occurred in patients younger than the median age, suggesting the existence of some specific demethylation mechanism targeting SST1 sequences other than the age-dependent stochastic process proposed in our "wear and tear" model [34]. We found that SST1 hypomethylation associated with the down-regulation of HELLS (Helicase Lymphoid-Specific Enzyme) [35], a DNA-helicase that plays an essential role in the maintenance of proper levels of methylation of repetitive DNA elements [42]. SST1 hypomethylation associated with changes in the histone code of these sequences [35], and with their transcriptional expression in the form of a long non coding RNA (tumor-associated NBL2 transcript, TNBL) stable throughout the mitotic cycle, that formed a perinucleolar aggregate in the proximity of a subset of SST1 loci during interphase $[43,44]$. The transcription of SST1 sequences had been previously reported, albeit it was regarded as the product of run-through transcription rather than SST1 specific promoter activity [37]. Despite the evidence of the hypomethylation of SST1 sequences as a somatic alteration putatively contributing to CRC and other cancer types, its phenotypic effects in cancer cells are still unclear.

\subsection{The Role of Aneuploidy in Cancer}

Cancer cells exhibit numerous types of genetic alterations, i.e., chromosomal rearrangements, amplifications, deletions, point mutations, etc. An abnormal number of chromosomes, or aneuploidy, is one of the earliest discovered and most prevalent characteristics of cancer cells. Around $90 \%$ of solid tumors exhibit some degree of aneuploidy. More than one century ago, Theodor Boveri proposed that aneuploidy could, in fact, promote 
malignant transformation [45,46]. In the 1970s, before the era of cellular oncogenes and tumor suppressor genes, there was a general support for this view [47]. Whether aneuploidy is the driving force of malignant transformation is still debated [48].

Aneuploidy is detrimental to the fitness of non-malignant cells during development or when introduced experimentally. However, it is tolerated by cancer cells, and, in some contexts, it might even contribute to their fitness [49]. Aneuploidy can be generated by different mechanisms. After chromosomal alignment in metaphase, sister chromatids are segregated during anaphase. In most cells, cytokinesis occurs simultaneously, causing the cytoplasm to divide into two daughter cells accommodating the newly segregated chromosomes [50]. The failure of these processes can affect genomic duplication fidelity. Furthermore, failures during cytokinesis can lead to complete genome duplication, or tetraploidy [51].

\subsection{The Importance of Tetraploidy in Cancer}

Genome-doubling and, consequently, tetraploidy is perhaps one of the most underestimated precursors of aneuploidy and chromosomal instability in human cancers [48]. Tetraploid cells are substantially more tolerant to deleterious mutations, since they harbor multiple copies of every gene, thus facilitating cell survival in a mutation-prone environment such as that associated with many types of cancers. In addition, tetraploidy may trigger chromosomal instability (CIN), probably due to centrosome abnormalities and duplicated chromosome mass, leading to aneuploidy [52,53]. There is experimental evidence directly linking tetraploidy with the onset of tumorigenesis in mice [53,54].

Analyses of chromosome copy number alterations of human cancers have shown that in the ontogenic genealogy of around one third of all solid tumors, a prior doubling event of the genome can be detected. These cancers have a post genome-doubling relative higher rate of chromosome gain and losses $[55,56]$. Tetraploid cell lines tolerate chromosomal segregation errors better than their diploid precursors $[56,57]$. While aneuploidy generates allelic imbalances that can be straightforwardly detected using molecular techniques, such as fingerprinting (reviewed in [58]), comparative genome hybridization arrays (aCGH) ([59], reviewed in [60]), SNP arrays [61] and even methylation arrays [62], tetraploidy evades detection using these techniques because the relative chromosomal content, allele balance and presumably methylation profiles remain unaltered.

\subsection{TP53 and Aneuploidy in Cancer}

The protein of Tumor Suppressor Gene P53 (TP53) monitors several aspects of DNA repair and cell division and contributes to suppressing tumor progression by hindering the division of cells with damaged DNA. Because of this, TP53 has been named the "guardian of the genome" [63]. TP53 mutations are very common in cancer [64] and according to TCGA data, they are the only cancer gene mutations significantly associated with CIN [65]. They also associate with tumors displaying evidence for genome duplication [66]. Moreover, it has been shown that wild type p53 blocks the growth of tetraploid cells, through G1 arrest $[53,67]$.

In this work, we provide experimental evidence for a link between the demethylation of the pericentromeric SST1 repeats and the onset of tetraploidy in human CRC cells in culture and for the association of strong demethylation of SST1 with mutations in TP53 in primary CRC.

\section{Materials and Methods}

\subsection{Cell Lines and Tumor Samples}

Colorectal cancer cell lines LS174T (CL-188), HCT116 (CCL-247), DLD-1 (CCL-221) and ovarian cell line OV-90 (CRL-11732) were obtained from the American Type Culture Collection (ATCC). Primary CRCs with matched normal tissue from 148 patients were obtained as frozen specimens from the Cooperative Human Tissue Network (CHTN, https:/ / www.chtn.org/). Informed consent was obtained and managed by the CHTN at 
the time of sample collection, following US regulations and the guidelines of the Declaration of Helsinki [68]. Approval to collect samples, extract DNA and perform analyses was obtained from the Institutional Review Board (IRB) of the Sanford-Burnham-Prebys (SBP) Medical Discovery Institute. Additional approval was obtained from the IRB of the IGTP to further analyze DNA samples in this study (approval code PI-18-252, 14 December 2018).

The identity of all the cells used in this work, as well as their derived clones, was validated by STR analysis using AmpFLSTR ${ }^{\mathrm{TM}}$ Identifiler ${ }^{\mathrm{TM}}$ Plus PCR Amplification Kit (Cat n:4486467, ThermoFisher Scientific, Waltham, MA, USA) using the provided protocol. Sequencing results were analyzed using GeneMapper ID v3.2 (Applied Biosystems, Waltham, MA, USA) and analyzed with Expasy Cellosaurus tool CLASTR 1.4.4 [69]. Data are provided in Supplementary Materials. All cell lines were confirmed to be mycoplasmafree by PCR analysis, prior to the initiation of the experiments and then regularly during the experimental timeframe.

\subsection{Cell Culture Conditions}

LS174T, HCT116 and DLD-1 cell lines were cultured in DMEM:F12 medium supplemented with $10 \%$ fetal bovine serum (FBS), $2 \mathrm{mM}$ L-glutamine, $1 \mathrm{mM}$ sodium pyruvate (NaPyr) and Antibiotic-Antimycotic. Ovarian cell line OV-90 was cultured in ATCC recommended media, 1:1 MCDB 105 medium containing a final concentration of $1.5 \mathrm{~g} / \mathrm{L}$ sodium bicarbonate and Medium 199 containing a final concentration of $2.2 \mathrm{~g} / \mathrm{L}$ sodium bicarbonate supplemented with 15\% FBS and antibiotic and antimycotic. All cells were cultured in ø100-mm culture plates, or in 24 -well plates with coverslips, in a $37^{\circ} \mathrm{C}$ incubator with $5 \% \mathrm{CO}_{2}$. Cells were grown until reaching $80-90 \%$ confluency before the collection or passage.

\subsection{Isolation of Single Cell-Derived LS174T Cell Clones}

LS174T and OV-90 cell line subcloning was performed using the limiting dilution method [70], as we have already performed in previous works for the isolation of spontaneous frameshift mutations in MMR genes in CRC cells with microsatellite instability (MSI) and to study their phenotype consequences [71]. Cells were counted after the addition of Trypan Blue 0.4\% 1:1 and diluted in complete medium to a concentration of 5 cells $/ \mathrm{mL}$ $(0.5$ cells $/ 100 \mu \mathrm{L})$. Moreover, $100 \mu \mathrm{L}$ of this dilution were seeded into each well of 96 plates and incubated at $37^{\circ} \mathrm{C}$. Cell growth was monitored by microscopy. The occasional presence of more than a single growth focus during culture was used as indication of non-clonality, and those cultures were discarded.

\subsection{Nuclei Size Measurement}

Cell morphology was studied by fluorescence microscopy after phalloidin and DAPI staining (Phalloidin-iFluor 594 Reagent, ab176757-Abcam). Cells were cultured in 24-well plates with glass coverslips inside until they reached $70-80 \%$ confluence. Then, the culture medium was carefully removed and washed once with PBS. Cells were fixed by incubation with 3-4\% formaldehyde in PBS at room temperature for $20 \mathrm{~min}$. The fixation solution was aspirated, and fixed cells were washed 3 times with PBS. To increase permeability, cells were incubated in PBS $+0.1 \%$ Triton X-100 for 5 min and washed with PBS 3 times. Next, $100 \mu \mathrm{L}$ of $1 \times$ Phalloidin conjugate $(1 \mu \mathrm{L}$ Phalloidin-iFluor $5941000 \times$ in $1 \mathrm{~mL}$ PBS $+1 \%$ BSA) was added to each coverslip. They were incubated at room temperature for $60 \mathrm{~min}$, protected from light. Finally, $100 \mu \mathrm{L}$ of PBS $+1 \mu \mathrm{g} / \mathrm{mL}$ DAPI (Cat N.: D1306Thermo Fisher Scientific, Waltham, MA, USA) were added to stain and visualize the nuclei. Lastly, 3 washes with PBS were performed to remove DAPI excess. The samples were dehydrated by immersion in $95 \%$ ethanol during $15 \mathrm{~s}$ and left to dry for $10 \mathrm{~min}$ in total darkness and mounted with ProLong Gold antifade reagent (Invitrogen, Thermo Fisher Scientific, Waltham, MA, USA). Samples were observed and photographed by fluorescence microscopy (LEICA DM1600B Microscope-LAS X Software). Fluorescence microscopy 
images $(200 \times)$ were analyzed with ImageJ Software [72]. The area of at least 200 nuclei was quantified per sample.

\subsection{Karyotyping}

Karyotypes were prepared from mitotic cells arrested in metaphase using colcemid, lysed in hypotonic solution ( $\mathrm{KCl} 0.075 \mathrm{M})$, fixed with Carnoy's solution (methanol:glacial acetic acid, 3:1) and stained according to the G-banding pattern, following standard procedures. The analyses were conducted with cells of the parental cell lines and derived single-cell clones at different time points of the culture after single-cell clone isolation. Karyotypes with tetraploidy were true tetraploid and not mixtures of two diploid cells, as determined by the mitotic patterns under microscopy, as well as the sparse cell densities in the cultures treated with colcemid for mitotic arrest.

\subsection{DNA and RNA Extraction}

Genomic DNA from cell lines was isolated using Maxwell ${ }^{\circledR} 16$ Instrument and the Maxwell $^{\circledR} 16$ DNA Purification Kit (Cat.\# AS1020, Promega, Madison, WI, USA) following the protocol provided. DNA concentration was measured by NanoDrop ${ }^{\mathrm{TM}}-1000 \mathrm{UV} / \mathrm{Vis}$ Spectrophotometer (Thermo Fisher Scientific, Waltham, MA, USA) and visualized in an agarose gel. Total RNA from cell lines was isolated using Maxwell ${ }^{\circledR} 16$ Instrument and the Maxwell $^{\circledR} 16$ LEV simplyRNA Cells Kit (Cat.\# AS1270, Promega, Madison, WI, USA) using the protocol provided. RNA quality control and integrity was measured using Agilent 2100 Bioanalyzer (Agilent Technologies, Santa Clara, CA, USA). All samples had an RNA Integrity Number (RIN) above 9.

\subsection{LINE-1 MS-QPCR}

LINE-1 MS-QPCR is a technique developed to estimate the ratio between unmethylated vs. methylated LINE-1 elements. This technique employs two sets of primers, one to amplify methylated (LINE1-mF and LINE1-mR) and the other unmethylated (LINE1-uF and LINE1-uR) LINE-1 molecules. Primer sequences are detailed in Figure S1. Two separate reactions were performed in duplicate for every sample. Conditions per reactions were: $5 \mu \mathrm{L}$ of Roche MasterMix SYBR-Green 2X, $100 \mathrm{ng}$ of bisulfite-transformed DNA, primers at $0.4 \mu \mathrm{M}$ each, $10 \mu \mathrm{L}$ final volume, 1 cycle of $95^{\circ} \mathrm{C} 10^{\prime}$ followed by 40 cycles of $95^{\circ} \mathrm{C} 10^{\prime \prime}, 60^{\circ} \mathrm{C} 10^{\prime \prime}$ and $72^{\circ} \mathrm{C} 12^{\prime \prime}, 1$ cycle of $95^{\circ} \mathrm{C} 5^{\prime \prime}, 60^{\circ} \mathrm{C} 1^{\prime}$ and $97^{\circ} \mathrm{C}$. Quantification was made with LightCycler ${ }^{\circledR} 480$ Software using a relative quantification program with standard settings and calculating $\mathrm{Cts}$ by double derivative method. All measures were normalized vs. genomic DNA from DLD-1 cells. LINE-1 MS-QPCR provide the relative demethylation level of LINE-1 elements (LINE-1 RDL), i.e., an estimation of the ratio of demethylated vs. methylated LINE-1 sequences in the studied sample relative to that of DLD-1 genomic DNA. Therefore, higher RDL indicates higher demethylation, i.e., lower level of methylation. For the statistical analysis, LINE-1 RDL was log2 transformed to reduce the skewness of the distribution.

Albeit very similar in concept to LINE-1 MethyLight [30], LINE-1 MS-QPCR provides the ratio of unmethylated vs. methylated LINE-1 molecules from the same sample without relying on the amplification of any other type of repetitive elements, such as Alu elements. Thus, there is no effect of possible differences in Alu vs. LINE-1 abundance among samples due to germline or somatic copy number differences. Moreover, while LINE-1 MethyLight employs specific primers and internal probes for the methylated and unmethylated PCR reactions to increase specificity, LINE-1 MS-QPCR employs just specific primers but no internal fluorescent probes. We purposely selected this approach to increase the range of detected molecules in the unmethylated and in the methylated reactions. We estimated the specificity of the amplification by sequencing clones from the LINE-1 methylated reaction and from the LINE-1 unmethylated reaction (Figure S1). From the methylated LINE-1 reaction, the proportion of methylated CpG sites ranged from $58 \%$ and $100 \%$ (median value $91 \%$ ). A total of 9 out of 10 clones from the unmethylated 
reaction showed complete demethylation, and 1 showed $22 \%$ methylation (2 CpG sites methylated and 7 unmethylated, on a sequence that exhibited 4 polymorphisms in the 13 interrogated CpG sites), for a median value of $0 \%$ methylation. Thus, LINE-1 MS-QPCR is not restricted to fully unmethylated or methylated sequences but instead provides the ratio of sequences with 0 22\% methylation (unmethylated sequences) vs. 60-100\% methylation (methylated sequences).

\subsection{SST1 MS-QPCR}

SST1 MS-QPCR is similar to the LINE-1 MS-QPCR technique described above, but in this case providing the ratio between unmethylated SST1 vs. amplifiable methylationindependent SST1 sequences by using two sets of primers, one specific for unmethylated SST1 elements and the other amplifying SST1 elements irrespective of their methylation status (primer sequences are detailed in Figure S2). The primers for the methylationindependent SST1 sequences were SST1-F and SST1-R, which we employed for bisulfite sequencing in a previous publication [35]. These primers amplify a $317 \mathrm{bp}$ internal region of the consensus SST1 sequence containing 27-28 CpG sites, some of them polymorphic, and including the NotI site that we originally found hypomethylated by MS-AFLP DNA fingerprinting [34]. Analyzing our bisulfite sequencing data from LS174T cells, we determined the CpG sites that better estimated the overall methylation level of this region (Figure S2). We designed the primer SST1-U-F to amplify SST1 sequences with unmethylated CpG3 (avoiding both CpG4, with low correlation with overall methylation, and CpG5, highly polymorphic) and primer SST1-U-R to amplify unmethylated CpG17 and CpG18 that exhibited the highest correlation with the overall methylation value $(r=0.77$ and $r=0.79$, respectively, Figure S2). Specificity of SST1-U-F and SST1-U-R primers was estimated by bisulfite sequencing (Figure S2). QPCR conditions and calculation of SST1 RDL were identical to LINE-1 MS-QPCR also using DLD-1 genomic DNA as reference sample (see above). For the statistical analysis, SST1 RDL was $\log 2$ transformed to reduce the skewness of the distribution.

SST1 MS-QPCR exhibited strong concordance with our previous results using bisulfite sequencing (correlation $=0.73$, CI95\% $=[0.54,0.85]$, Pearson's test $p=7.9 \times 10^{-8}$, Figure S2). Considering bisulfite sequencing (originally used to classify cases into nochange/demethylated or strongly demethylated [35]) as gold standard, MS-QPCR was very accurate to detect strongly demethylated samples (max accuracy $=0.96, \mathrm{AUC}=0.79$, $p=0.01$ ). Samples with moderate changes in SST1 methylation were not detected by MS-QPCR, which was very likely because they do not have very low methylated SST1 molecules that are targeted by SST1-U-F and SST1-U-R primers.

\subsection{Bisulfite Sequencing}

Genomic DNA was treated with sodium bisulfite using EZ DNA Methylation Kit (Cat.\#D5001, Zymo Research, Irvine, CA, USA). Bisulfite treated samples were used as a template for PCR and QPCR amplification of SST1/LINE-1 sequences.

A SST1-specific PCR was designed to cover a total 317 bp, including 27-28 CpGs including the NotI site of the band previously identified by MS-AFLP. The PCR Master Mix contained: $1 \times$ Buffer, $0.125 \mathrm{nM}$ dNTPs, 0.25 units of Taq DNA Polymerase (Roche) and $0.4 \mathrm{mM}$ of primers SST1-F and SST1-R (Figure S2). The PCR program consisted of 1 cycle at $95^{\circ} \mathrm{C}$ for $5 \mathrm{~min}$, followed by 35 cycles of denaturation at $95^{\circ} \mathrm{C}$ for $15 \mathrm{~s}$, annealing at $55^{\circ} \mathrm{C}$ for $30 \mathrm{~s}$ and extension at $72{ }^{\circ} \mathrm{C}$ for $60 \mathrm{~s}$, ending at $72{ }^{\circ} \mathrm{C}$ for $5 \mathrm{~min}$ to complete extension.

For bisulfite sequencing, $1 \mu \mathrm{L}$ of SST1-F/R PCR product was cloned into pSC-Aamp/kan vector using Strataclone ${ }^{\mathrm{TM}}$ PCR Cloning Kit (Cat.\#240205, Agilent Technologies, Santa Clara, CA, USA) following manufacturer's instructions and transformed into E. coli Statataclone SoloPack competent cells. Transformed cells were selected onto LB plates containing Ampicillin $(50 \mu \mathrm{g} / \mathrm{mL})$ and X-Gal $(40 \mu \mathrm{g} / \mathrm{mL})$. To identify bacterial colonies harboring the vector with the cloned PCR product, colony PCRs were performed using universal primers T3 and T7 [73]. Amplicon size was analyzed by gel electrophoresis and those 
reactions that rendered a correct size fragment were sequenced (GATC Services, Eurofins Genomics, Louisville, KY, USA) and analyzed with CLC Main Workbench 5.6.1 program.

\subsection{Illumina HM450K Methylation Arrays}

Genomic DNA from tumors and matching normal tissues from 30 CRC patients were previously analyzed using Illumina HM450K arrays, following standard procedures [74]. The generated idat files were preprocessed and filtered using RnBeads [75], discarding data from $X$ and $Y$ chromosomes. Type-I vs. Type-II probe bias was corrected using the BMIQ method from the wateRmelon package [76].

\subsection{Gene Expression Arrays and Gene Set Enrichment Analysis}

RNA was extracted from cultured cells using Maxwell ${ }^{\circledR}$ RSC simplyRNA Cells Kit on a Maxwell AS2000 equipment (Promega, Madison, WI, USA). Quantity and quality of RNA were verified on an Agilent 2100 Bioanalyzer. cDNA synthesis, labeling and hybridization on Clariom S Arrays from Thermo Fisher Scientific were performed by the Genomics Unit of Josep Carreras Leukaemia Research Institute. Raw data files were preprocessed using RMA (oligo R package). Gene set enrichment analysis was performed using GSEA, comparing with MSigDB hall mark gene set [77]. Full input dataset and output in HTML, specifying the running parameters, are provided as Supplementary Material.

\subsection{Statistical Analyses}

All statistical analyses were performed using R [78]. Normality was tested using Shapiro's test. Variables normally distributed were analyzed using parametric tests (e.g., t-test, ANOVA). Variables not normally distributed were analyzed using Wilcox's exact test. When appropriate, multiple hypothesis correction was performed using the false discovery rate (FDR) method implemented in p.adjust function. Comparison of coefficient of variation $(C V=\sigma / \mu)$ was performed using the asymptotic Feltz-Miller's test [79].

\section{Results}

\subsection{Isolation of LS174T Single Cell-Derived Clones}

To test the hypothesis that the demethylation of the SST1 pericentromeric repetitive sequences could increase the probability of undergoing mitotic errors, we designed a strategy to study the effects of variations in the SST1 demethylation level in chromosomal changes in isogenic cells. Among 14 CRC cell lines, LST174T cells exhibited the lowest average level (55 $\pm 25 \%)$ and the highest range (19-88\%) of SST1 methylation [35]. This suggested that it would be feasible to isolate single cell clones with different levels of SST1 methylation. We hypothesized that SST1 demethylation could be accompanied by an increased rate of chromosomal alterations, observable after long-term growth. The approach was facilitated because LS174T is near-diploid (45 X, after the loss of one of the $X$ chromosomes), with no reported chromosomal instability. It exhibits MSI due to the hypermethylation of $h M L H 1$ but not CIMP [80]. We generated a collection of 30 single-cellderived clones using the limited dilution method, from which we randomly chose 14 (C1 to C14). The identity of these individual clones as well as the original LS174T cells was confirmed by short tandem repeat (STR) analysis (Supplementary Materials).

\subsection{LS174T Is a Mixture of Normal-Sized and Large-Nucleus Cells with Different Ploidy}

We intended to subject these LS174T single-cell clones to long term culture, but clear differences in cell size among them were observed right after their initial expansion. The cell staining with phalloidin and DAPI revealed that cells from clones C5-C8 had substantially larger nuclei in interphase (Figure 1A). The clustering of the clones based on their nuclei area yielded two distinct groups: a group comprising clones $\mathrm{C} 1-\mathrm{C} 4$ and $\mathrm{C}$-C14, with a nuclei area of $72.5 \pm 26.2 \mu \mathrm{m}^{2}$, and a group comprising clones C5-C8, with a nuclei area of $132.1 \pm 50 \mu^{2}$ (Figure 1B). The nuclei area of the parental cell line was $89.7 \pm 37.8 \mu \mathrm{m}^{2}$ but exhibited a trimodal distribution with peaks at approximately 65,115 and $180 \mu \mathrm{m}^{2}$ 
(Figure S3) that could not be explained just by the coexistence of cells in G0/G1 vs. cells in $\mathrm{S} / \mathrm{G} 2$. The doubling of a nucleus's volume corresponds to a $2^{2 / 3} \approx 1.6$ times increase in its area. Thus, nuclei with areas of $115 \mu \mathrm{m}^{2}$ would correspond to roughly two times the volume of nuclei with areas of $65 \mu \mathrm{m}^{2}$ and nuclei with areas of $180 \mu \mathrm{m}^{2}$ over four times that. To estimate the proportion of cells with large nuclei, a threshold of $115 \mu \mathrm{m}^{2}$ was set based on the nuclei distribution of the parental LS174T cells. About 22\% of the LS174T cells had a nucleus larger than $115 \mu \mathrm{m}^{2}$. Over $50 \%$ of the cells in clones C5-C8 had a nucleus larger than that. Clones C1-C4, C10-C11 and C13-C14 had less than 10\% of nuclei over $115 \mu^{2}$. Two LS174T-derived clones classified as small according to their average nuclei area exhibited a higher proportion of nuclei larger than $115 \mu \mathrm{m}^{2}$, i.e., C9 (11\%) and C12 $(15 \%)$ (Figure $1 \mathrm{C})$. Flow cytometry analysis indicated that clones C5-C8 had approximately two times greater genomic content than clones C1-C4 and C9-C14 (Figure S4).
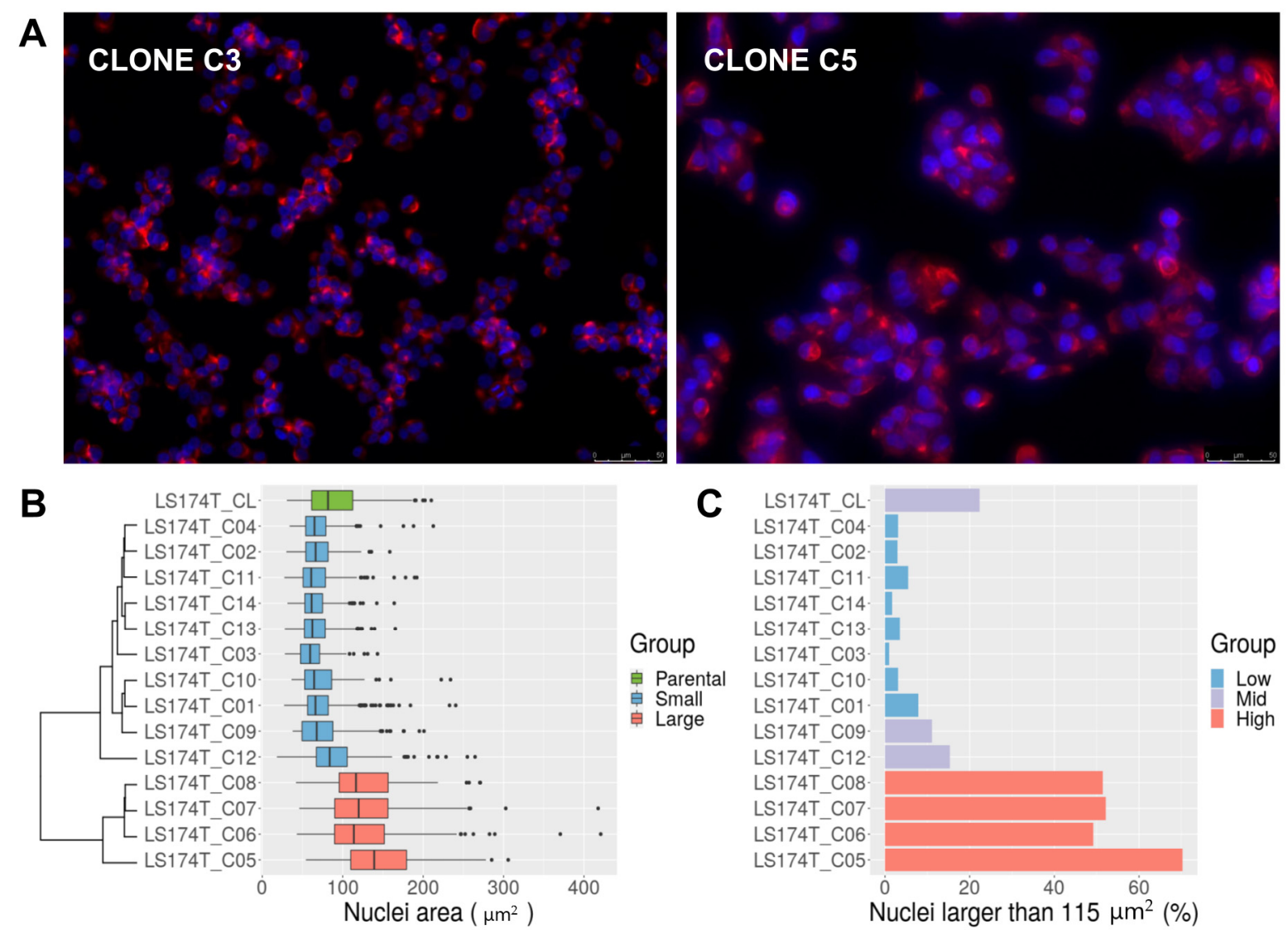

Figure 1. (A) Morphological analysis of LS174T clones. The figure shows a small cell size clone (C3) and a large cell size clone (C5) stained with phalloidin (red, cytoskeleton) and DAPI (blue, nuclei). Pictures were taken at $200 \times$ magnification. Scale bar $50 \mu \mathrm{m}$ is shown in the bottom right corner of the pictures. (B) Nuclei area of LS174T and derived clones, measured by microscopy after DAPI staining. The parental cell line (CL) in green. Clones are colored according to the average nuclei size into small (blue) and large (red) and classified by unsupervised clustering based on the difference of their average nuclei size (dendrogram on the left). (C) Percentage of nuclei with areas larger than $115 \mu \mathrm{m}^{2}$ in LS174T and derived clones. Most of the clones exhibited a low proportion (less than 10\%, low group, blue) of nuclei above $115 \mu \mathrm{m}^{2}$. The parental cell line (CL) and clones C9 and C12 exhibited a larger proportion (10 25\%, mid group, in purple). Clones C5-C8 exhibited around $50 \%$ of nuclei larger than that value (high group, in red).

Karyotyping revealed that parental LS174T was a mixture of near-diploid $(45, X)$ and near-tetraploid $(90, X X)$ cells, with the sporadic appearance of $46, X$ cells with trisomy of chromosome 7 (Figure 2A). In agreement with the nuclei size and cytometry results, clones C5, C6, C7 and C8 were composed by near-tetraploid cells $(90, X X)$. Clones C1, C3, C4, C10 and C11 exhibited almost exclusively near-diploid nuclei $(45, X)$. Clones C2, C13 and 
C14 exhibited cells with 46,X and trisomy of chromosome 7 (Figure 2B). Clones C9 and $\mathrm{C} 12$ were a mixture of near-diploid and near-tetraploid cells. Our interpretation was that some cells of C9 and C12 underwent spontaneous tetraploidization during the culturing time after isolation, indicating that genome duplication is a dynamic process in LS174T cells and not the result of a single past event. However, it was also possible that clones C9 and C12 were derived from two (or more) cells with different ploidy and substantially different proliferation rates favoring a larger proportion of near-diploid cells after several rounds of cell division. To investigate this possibility, we selected clones C8 and C11 as representative of pure near-tetraploid and near-diploid cells, respectively, and determined their karyotype after 60 days of culture, equivalent to over 40 cell divisions (Figure S5). Clone C 8 cells exhibited an almost stable near-tetraploid karyotype. At time $0,100 \%$ of the metaphases were near-tetraploid (97 out of 97). After 60 days of culture, we found 3 mitotic cells out of 72 with $n>90$ chromosomes (Figure 2C). No near-diploid cells were found at any time point in this clone. On the other hand, clone C11 cells exhibited mostly neardiploid karyotype at time 0 , with only 1 near-tetraploid metaphase out of the 95 mitoses analyzed (1\%), but we found 10 out of 75 mitoses $(13 \%)$ with near-tetraploid metaphases after 60 days of culture ( $p=0.003$, Fisher's exact test) (Figure 2C). Since the individual cells analyzed for their karyotype originated from a clone that was near-diploid and the mitoses were typical of single cells and not mixtures of different cells (Figure 2D), we concluded that these near-tetraploid cells originated from near-diploid parent cells. Modeling the generation of near-tetraploid cells in clone C11, we estimated that approximately $3 \%$ of the mitosis resulted in spontaneous tetraploidization (Figure S6).
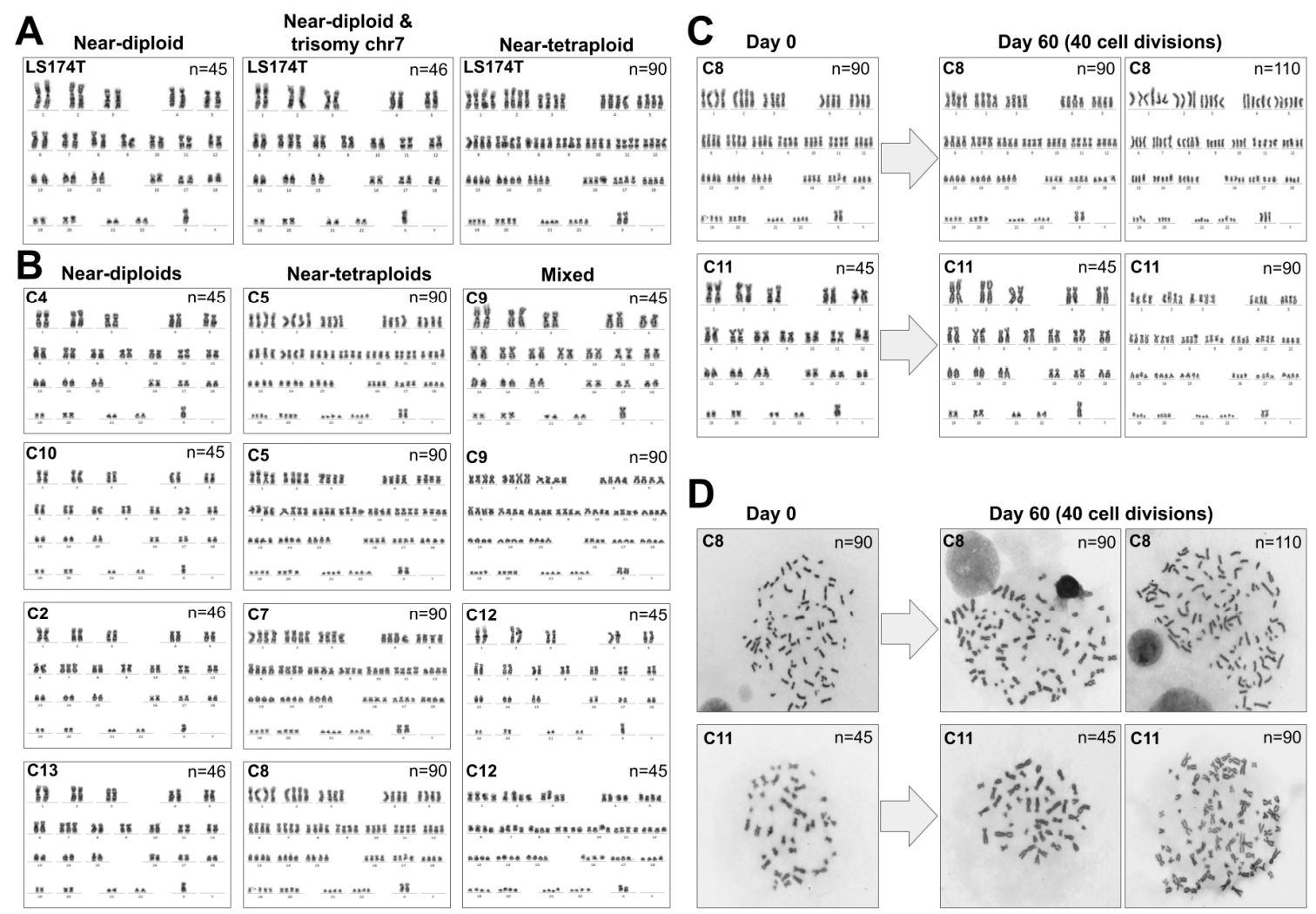

Figure 2. (A) Karyotypes of the parental cell line LS174T exhibited a mixture of near-diploid ( $\mathrm{n}=45$, left), near-diploid with trisomy of chromosome 7 ( $n=46$, middle) and near-tetraploid cells $(n=90$, right). (B) Left, karyotypes of near-diploid clones $\mathrm{C} 4$ and $\mathrm{C} 10(\mathrm{n}=45)$ and near-diploid clones $\mathrm{C} 2$ and $\mathrm{C} 13$ with trisomy of chr7 $(\mathrm{n}=46)$; middle, near-tetraploid clones C5, C6, C7 and C8; right, clones with mixture of karyotypes C9 and C12. (C) Karyotypes of LS174T clones C8 and C11. At time 0 (left), C8 cells were pure near-tetraploids, and C11 cells were almost pure near-diploids. After 60 days of culture (right), C8 cells remained mostly near-tetraploid with the occasional appearance of higher ploidy cells, while C11 cells exhibited $13.3 \%$ of near-tetraploid cells. (D) Metaphases of the karyotypes presented in panel C. 


\subsection{Analysis of Other Cancer Cell Lines}

To extend these observations, we analyzed the degree of anisonucleosis (variability in cell nuclei size) by calculating the coefficient of variation (CV) of the nuclei area as a proxy for the genomic content in HCT116 and DLD-1 CRC cell lines. The level of anisonucleosis in LS174T (CV $=42 \%)$ was higher than in HCT116 $(\mathrm{CV}=33 \%$, asymptotic test $\left.p=4.2 \times 10^{-7}\right)$ and DLD-1 $(\mathrm{CV}=38 \%$, asymptotic test $p=0.036)$, despite the three cell lines being MSI and originally described as mainly diploid or near-diploid. Moreover, the proportion of cells with large nuclei (over three times the modal nucleus volume, where the modal nucleus volume was assumed to correspond to diploid or near-diploid cells in G0/G1) was significantly higher in LS174T (12.7\%) than in DLD-1 (7\%, Fisher's test $p=0.004)$ and HCT116 (1\%, Fisher's test $\left.p=6.3 \times 10^{-16}\right)$ (Figure S7). The higher incidence of polyploidy in our cultures of LS174T cells $(12.7 \%)$ than in the first report describing this cell line (6.1\%) [81] is likely due to the accumulation of near-tetraploid cells during successive culture passages. Of note, near-tetraploid cells have been also observed in LS-180, the LS174T parental cell line [81], albeit at a lower rate $(2.2 \%$, according to the ATCC). Due to the absence of significant SST1 demethylation in DLD-1 and HCT116 cell lines (Figure S7), a similar study to isolate single cell clones with substantially different levels of SST1 methylation was not feasible.

We generated 15 single-cell clones from the ovarian cancer cell line OV-90, which displayed a wide range and a low average of SST1 methylation (50 $\pm 20 \%$ ) in our previously published study [35]. OV-90 was originally described as mainly diploid, albeit displaying complex karyotypic changes involving chromosomal rearrangements, translocations, deletions and duplications [82]. In contrast with LS174T, OV-90 is microsatellite stable (MSS) and harbors a mutant TP53 gene. The single-cell clones of OV-90 showed aberrant and very variable chromosomal content with an overall distribution of hypertriploidyhypopentaploidy, with numerous multipolar spindle mitoses indicative of active chromosomal instability (Figure S8). In addition to chromosomes with two and three copies, the karyotypes presented several chromosomes with four copies (Figure S8). These results are consistent with an ancestral tetraploid cell lineage. All 15 subclones exhibited very high chromosomal instability and ploidy variability, and no distinctive groups based on their nuclei area or ploidy could be observed in the time frame of the cultures (data not shown).

\subsection{Chromosomal Content Correlates with SST1 Methylation Level in LS174T Cells}

We analyzed the methylation level of the SST1 sequences in the 14 LS174T-derived clones, as well as the LS174T parental cell line, using bisulfite sequencing (see Section 2.9). The methylation of individual SST1 elements within each single-cell derived clone was highly variable (Figure $3 \mathrm{~A}$ ). Only $10.7 \%$ of the methylation variance was explained by the differences among clones, while $89.2 \%$ reflected intra-clonal variability (ANOVA analysis). Despite this variability, the near-tetraploid clones (C5-C8) exhibited lower average methylation than the near-diploid clones $\left(30.1 \pm 2.8 \%\right.$ vs. $43.6 \pm 4.0 \%$, $t$-test $\left.p=1.0 \times 10^{-4}\right)$. The clones with mixed populations of near-diploid and near-tetraploid cells (C9 and C12) also exhibited low levels of methylation $(30.5 \pm 3.8 \%)$. These results indicated a significant inverse correlation between SST1 methylation and tetraploidization in LS174T cells $\left(\mathrm{r}^{2}=0.53\right.$, $p=0.002$, Figure $3 \mathrm{~B})$. 

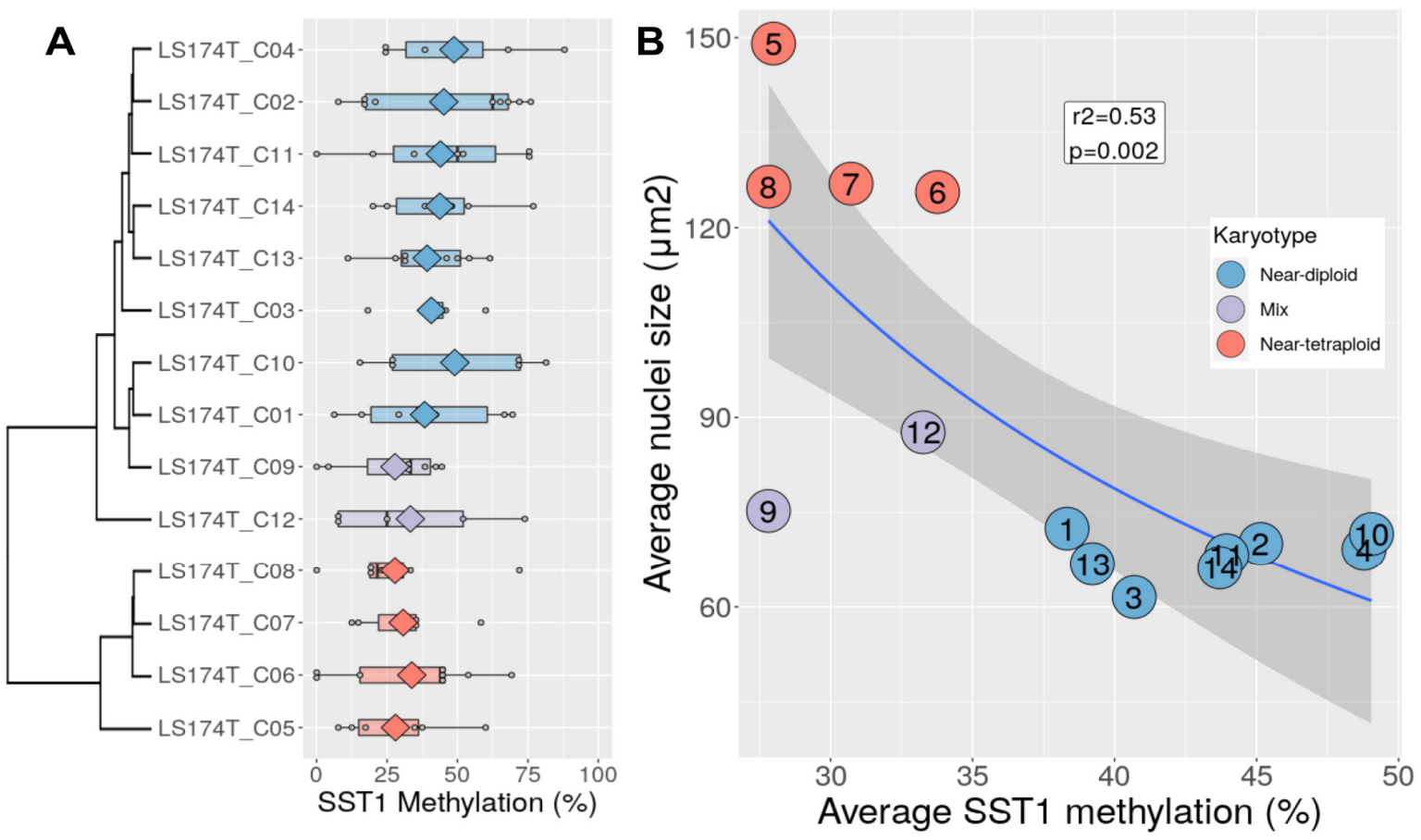

Figure 3. (A) SST1 methylation levels measured by bisulfite sequencing in LS174T-derived single cell clones. Clones are ordered according to their nuclei size-based clustering (see Figure 1) and colored according to their karyotype. Every grey dot represents the average methylation of an individually sequenced SST1 molecule. Diamonds indicate the average methylation level of all SST1 the molecules sequenced in every clone. (B) SST1 average methylation ( $x$-axis) vs. average nuclei size (y-axis) in LS174T-derived single-cell clones. Every dot represents the value of a LS174T-derived cell clone, colored according to its karyotype. The regression line (nuclei area $\sim 1 /$ methylation) and its $95 \%$ confidence interval are depicted in blue and dark grey, respectively. The inverse correlation between nuclei area and methylation was $\mathrm{r}=0.73$, $\mathrm{r}^{2}=0.53, p=0.002$.

\subsection{Transcriptional Profile Differences between Near-Diploid and Near-Tetraploid LS174T Cells}

We compared the transcriptional profile of near-tetraploid (clones C5-C8) vs. neardiploid (clones C3, C10, C11 and C14) LS174T cells using Affymetrix Clariom ${ }^{\mathrm{TM}} \mathrm{S}$ arrays (Supplementary Materials). The near-diploid and near-tetraploid LS174T subclones exhibited similar transcriptional profiles (Figure S9). A gene set enrichment analysis (GSEA) [77] revealed that the expressions of E2F targets, MYC targets and G2M checkpoint genes were significatively enriched in the near-tetraploid cells (Figure S10), consistent with the fact that the control of the cell cycle is altered in these cells [83].

\subsection{SST1 Demethylation Associates with LINE-1 Demethylation in Primary CRCS}

We then analyzed SST1 and LINE-1 methylation in 148 primary CRC tumors and their matching normal tissues using MS-QPCR, a technique that provides an estimation of the proportion of unmethylated target sequences, a value termed as the relative demethylation level (RDL, see methods). Clinicopathological, mutational and DNA methylation data from these 148 CRC are shown in Table S1. To benchmark MS-QPCR, 40 of these cases were chosen among those previously analyzed by bisulfite sequencing. We obtained very concordant results between both techniques $\left(\mathrm{r}=0.73, p=8 \times 10^{-8}\right.$, Figures S2 and S9).

SST1 RDL in tumors and matching normal tissues strongly correlated $(\mathrm{r}=0.64$, $p=3.9 \times 10^{-18}$, Figure 4A). Most tumors exhibited a degree of SST1 methylation very similar to that of their matching normal tissues, and the average methylation level was similar in both groups (paired $t$-test $p=0.07$, Figure 4B). Seven tumors, however, deviated from this trend and exhibited SST1 RDL values higher than the 95\% confidence interval of the regression model prediction. These tumors were classified as SST1 strongly demethylated (Figure $4 \mathrm{~A}, \mathrm{~B}$ ). The methylation of LINE-1 exhibited a very different behavior. We 
found no significant correlation between the tumor tissue and the matching normal tissues $(r=-0.06, p=0.56$, Figure 4C), and most tumors exhibited lower methylation than their matching normal tissues (paired $t$-test $p=6 \times 10^{-23}$, Figure 4D).
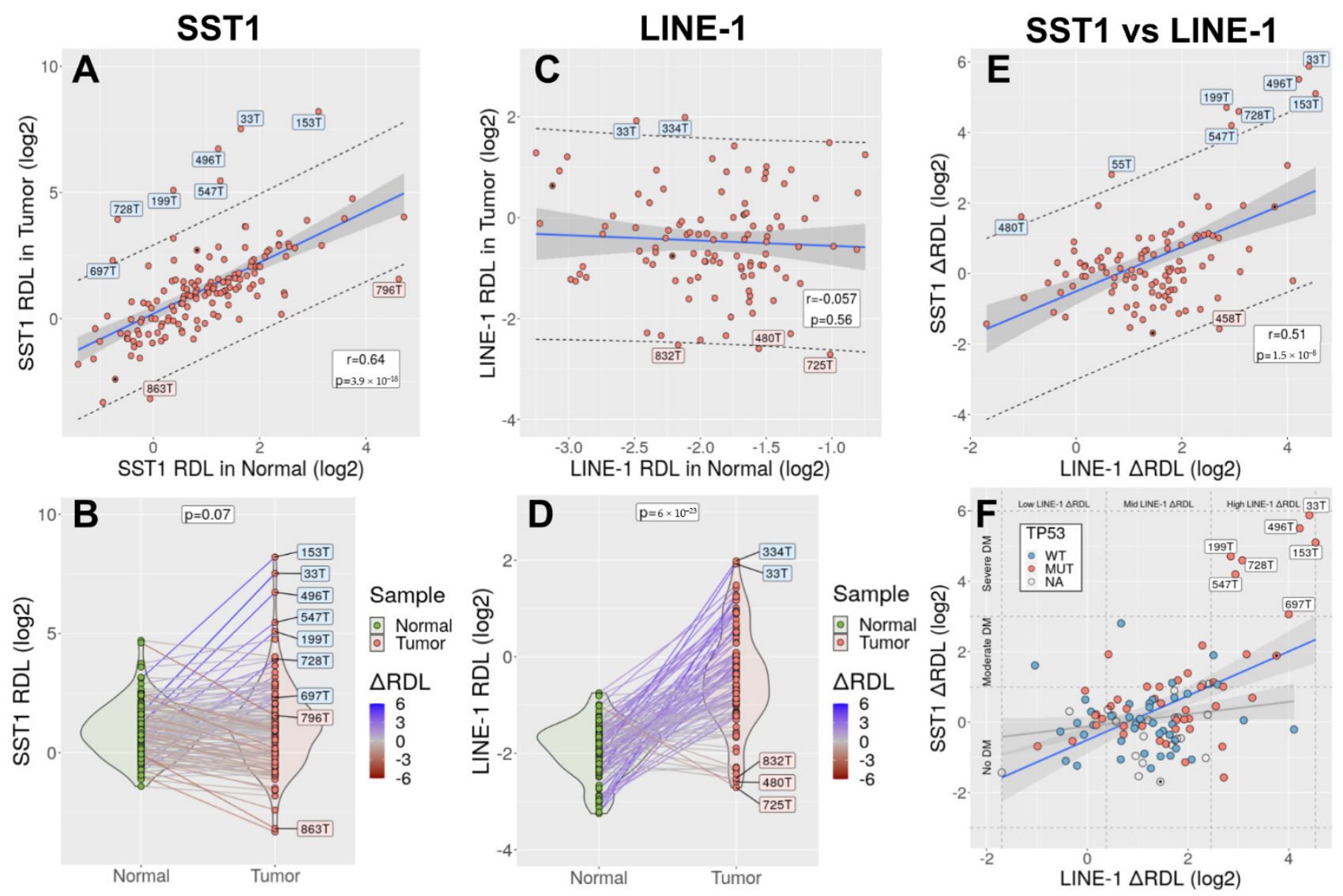

Figure 4. (A) Correlation between SST1 RDL in 148 CRC tumors ( $y$-axis) and matched normal tissues ( $x$-axis). Every dot represents a tumor. In blue, the regression line. Shaded in grey, the $95 \% \mathrm{CI}$ of the slope. The dashed lines indicate the $95 \%$ CI of the values predicted by the regression model. Labeled in blue and red, tumors with SST1 RDL above (strongly demethylated) and below the predicted upper limit of the $95 \% \mathrm{CI}$, respectively. Two metastases are indicated with an internal black dot. (B) SST1 RDL values in normal tissues (green) and tumors (red). Tumor and matched normal samples are connected by solid lines, colored according to their difference in SST1 RDL (somatic demethylation, $\triangle$ RDL). Tumors with SST1 RDL values outside the $95 \%$ CI of the regression model prediction (shown in panel A) are labeled. (C) Correlation between LINE-1 RDL in 107 tumors and matched normal tissues. Symbols as in panel A. (D) LINE-1 RDL values in normal tissues and tumors. Symbols as in panel B. (E) Correlation between SST1 $\triangle$ RDL and LINE-1 $\triangle$ RDL. Symbols as in panels A and C. (F) Correlation between LINE-1 and SST1 somatic demethylation in 107 CRCs. Tumors are colored according to their TP53 mutational status (WT: wild type; MUT: mutant; NA: not analyzed). The graph is divided with dashed lines in nine areas according to the levels of LINE-1 $\triangle$ RDL (horizontal axis, divided in low, mid and high demethylated) and SST1 $\triangle$ RDL (vertical axis, divided into no demethylated, moderately demethylated and strongly demethylated). Two regression models are depicted, one with all the samples (blue line) and the other excluding the SST1 strongly demethylated cases (grey line). The dark grey areas indicate the $95 \%$ CI of the slope.

We defined the somatic demethylation value ( $\triangle \mathrm{RDL}$ ) as the difference between RDL from the tumors and their matching normal samples, after log2 transformation. Thus, $\Delta \mathrm{RDL}=0$ indicates the same proportion of demethylated SST1 molecules in the tumor and the matching normal sample, $\triangle \mathrm{RDL}=1$ indicates that the proportion of demethylated SST1 molecules is two times larger in the tumor than in the normal, etc. All seven outlier cases classified as SST1 strongly demethylated exhibited SST1 $\triangle$ RDL $>3$.

SST1 somatic demethylation correlated with LINE-1 somatic demethylation $(\mathrm{r}=0.51$, $\mathrm{CI} 95 \%=[0.36-0.64], p=1.5 \times 10^{-8}$, Figure $\left.4 \mathrm{E}\right)$. This correlation was highly influenced by 
the few cases with strong SST1 somatic demethylation, all of them exhibiting high levels of LINE-1 somatic demethylation. Excluding these cases, the correlation between SST1 $\triangle$ RDL and LINE-1 $\triangle$ RDL was much lower, albeit still positive $(r=0.2, C I 95 \%=[0.009-0.39])$.

The genome-wide methylation profiling of 30 CRCs and their matching normal samples with Illumina HM450K arrays showed that LINE-1 somatic demethylation correlated with genome-wide demethylation ( $\mathrm{r}=0.68, p=4.4 \times 10^{-5}$, Figure S11C). When considering only the CpG sites not associated with CpG islands (those located $>2000$ bp apart from their closest CpG island), the correlation remained high $r=0.69, p=3.6 \times 10^{-5}$ (Figure S11C). This association was expected since LINE-1 methylation is widely considered a marker of global genome methylation. SST1 demethylation, on the other hand, did not correlate with genome-wide demethylation regardless of the analyzed subset of CPG sites (Figure S11C).

\subsection{SST1 Strong Demethylation Is Associated with TP53 Mutations in CRC}

CRCs were classified into three categories based on their SST1 $\triangle$ RDL: tumors with strong ( $\triangle \mathrm{RDL}>3, \mathrm{n}=7,4.7 \%)$, moderate $(1<\Delta \mathrm{RDL}<3, \mathrm{n}=18,12.2 \%)$ and without $(\Delta \mathrm{RDL}<1, \mathrm{n}=123,83.1 \%)$ somatic demethylation. Associations between SST1 somatic demethylation and clinicopathological characteristics of the 148 CRCs are shown in Table 1. SST1 somatic demethylation correlated with TP53 mutations in both comparisons (moderate or strong demethylation vs. rest, $p=0.0037$, and strong demethylation vs. rest, $p=0.012$, Fisher's test). To reduce ambiguity around the RDL measurement error influencing sample categorization, we also compared tumors without demethylation $(\triangle \mathrm{RDL}<1)$ vs. tumors with strong demethylation $(\triangle \mathrm{RDL}>3)$ and confirmed that the association remained statistically significant $(p=0.0037)$ despite the lower number of samples. Strong demethylation exhibited a borderline significant correlation with wild-type KRAS $(p=0.048)$. We also studied the association of the clinical and mutational characteristics with SST1 $\triangle$ RDL as a continuous variable without performing a categorical classification of the cases (Figure S12). There was a significant correlation of SST1 $\triangle$ RDL with TP53 mutations $(p=0.0015)$, with KRAS wild-type tumors $(p=0.017)$ and with African Americans $(p=0.007)$. In a multivariate regression analysis, only TP53 mutations remained statistically significant $(p=0.026)$.

Table 1. Association of SST1 demethylation with CRC genotype and phenotype.

\begin{tabular}{|c|c|c|c|c|}
\hline Parameter & $\begin{array}{c}\text { Not Demethylated } \\
\text { SST1 } \Delta \text { RDL }<1.0\end{array}$ & $\begin{array}{c}\text { Moderately } \\
\text { Demethylated } \\
\text { SST1 } \Delta \text { RDL }>1.0 \&<3.0\end{array}$ & $\begin{array}{c}\text { Strongly } \\
\text { Demethylated SST1 } \\
\Delta \text { RDL }>3.0\end{array}$ & Fisher's Test $p$-Value \\
\hline \multirow{2}{*}{ Gender } & Women $(n=59)$ & Women $(n=6)$ & Women $(n=2)$ & $p 1=0.19$ \\
\hline & Men $(n=64)$ & Men $(n=12)$ & $\operatorname{Men}(n=5)$ & $p 2=0.46$ \\
\hline \multirow{2}{*}{ Age } & $<66$ y/o $(\mathrm{n}=57)$ & $<66$ y/o $(\mathrm{n}=10)$ & $<66$ y/o $(\mathrm{n}=5)$ & $p 1=0.27$ \\
\hline & $>66$ y/o $(n=66)$ & $>66$ y/o $(\mathrm{n}=8)$ & $>66$ y/o $(n=2)$ & $p 2=0.27$ \\
\hline \multirow{2}{*}{ Ethnic } & Caucasian $(\mathrm{n}=94)$ & Caucasian $(\mathrm{n}=9)$ & Caucasian $(\mathrm{n}=3)$ & $p 1=0.05$ \\
\hline & Afr.Am. $(n=18)$ & Afr.Am. $(n=6)$ & Afr.Am. $(n=1)$ & $p 2=0.58$ \\
\hline \multirow{2}{*}{ Tumor Location } & Proximal $(\mathrm{n}=69)$ & Proximal $(\mathrm{n}=10)$ & Proximal $(n=2)$ & $p 1=0.38$ \\
\hline & Distal $(n=50)$ & Distal $(\mathrm{n}=8)$ & Distal $(\mathrm{n}=5)$ & $p 2=0.24$ \\
\hline \multirow{2}{*}{ Dukes' stage } & IS-A-B $(n=52)$ & IS-A-B (n = 9) & IS-A-B $(n=4)$ & $p 1=0.39$ \\
\hline & C-D-M (n = 71) & C-D-M (n = 9) & C-D-M (n = 3) & $p 2=0.70$ \\
\hline \multirow{2}{*}{ MSI status } & MSS $(n=102)$ & $\operatorname{MSS}(n=17)$ & $\operatorname{MSS}(n=6)$ & $p 1=0.37$ \\
\hline & MSI $(n=21)$ & MSI $(n=1)$ & $\operatorname{MSI}(n=1)$ & $p 2=1.00$ \\
\hline \multirow{2}{*}{ TP53 } & $\mathrm{WT}(\mathrm{n}=44)$ & $\mathrm{WT}(\mathrm{n}=5)$ & $\mathrm{WT}(\mathrm{n}=0)$ & $p 1=0.0037^{* *}$ \\
\hline & MUT (n = 32) & $\operatorname{MUT}(\mathrm{n}=11)$ & $\operatorname{MUT}(\mathrm{n}=7)$ & $p 2=0.012 *$ \\
\hline
\end{tabular}


Table 1. Cont.

\begin{tabular}{|c|c|c|c|c|}
\hline Parameter & $\begin{array}{c}\text { Not Demethylated } \\
\text { SST1 } \Delta \text { RDL }<1.0\end{array}$ & $\begin{array}{c}\text { Moderately } \\
\text { Demethylated } \\
\text { SST1 } \Delta \text { RDL }>1.0 \&<3.0\end{array}$ & $\begin{array}{c}\text { Strongly } \\
\text { Demethylated SST1 } \\
\Delta \mathrm{RDL}>3.0\end{array}$ & Fisher's Test $p$-Value \\
\hline \multirow{2}{*}{$K R A S$} & $\mathrm{WT}(\mathrm{n}=75)$ & $\mathrm{WT}(\mathrm{n}=12)$ & $\mathrm{WT}(\mathrm{n}=7)$ & $p 1=0.18$ \\
\hline & MUT $(\mathrm{n}=48)$ & $\operatorname{MUT}(n=6)$ & $\operatorname{MUT}(n=0)$ & $p 2=0.048^{*}$ \\
\hline \multirow{2}{*}{$B R A F$} & $\mathrm{WT}(\mathrm{n}=112)$ & $\mathrm{WT}(\mathrm{n}=16)$ & $\mathrm{WT}(\mathrm{n}=4)$ & $p 1=0.25$ \\
\hline & $\operatorname{MUT}(\mathrm{n}=10)$ & MUT $(n=2)$ & $\operatorname{MUT}(\mathrm{n}=2)$ & $p 2=0.10$ \\
\hline
\end{tabular}

$p 1$ : Fisher's test $p$-value comparing not-demethylated tumors vs. the rest (demethylated and strongly demethylated). $p 2$ : Fisher's test $p$-value comparing strongly demethylated tumors vs. the rest. *: $p$-value $<0.05$. ${ }^{* *}$ : $p$-value $<0.01$. In parenthesis, the number of informative cases in each category. In Ethnic, Afr.Am.: African American. In Duke's stage, tumors were grouped into in situ (IS, $n=1)$, Duke's A ( $n=7)$ and Duke's B (B, $n=54)$ vs. Duke's C $(n=58)$, Duke's D $(n=23)$ and metastases $(M, n=2)$. WT: wild-type. MUT: mutant. Some of the total number of samples do not match the total 148 cases sample due to incomplete information.

\section{Discussion}

The original aim of this work was to explore the link between the demethylation of SST1 elements and chromosomal instability in human CRC cells. The approach employed LS174T, an MSI and mainly near-diploid CRC cell line with low average level and high variability ( $55 \pm 25 \%)$ of SST1 methylation [35]. We found that right after isolation, some LS174T single cell-derived clones had a larger average cell and nuclei size (clones C5 to C8, Figure 1) with near-tetraploid karyotype (Figure 2). In agreement with our initial hypothesis, near-tetraploidy in LS174T clones was strongly associated with lower levels of methylation of SST1 elements $\left(r^{2}=0.53, p=0.002\right.$, Figure 3$)$.

Near-tetraploid cells were also found in originally near-diploid clones after very few cell divisions (clones C9 and C12, Figure 2B). Longer culturing time ( $\sim 40$ cell divisions) of pure near-diploid cells (clone C11) generated near-tetraploid cells, reaching around 13\% of the final population (Figure 2C). This showed that spontaneous tetraploidization in LS174T was not the result of a single past event, but the result of an intrinsic and active chromosomal segregation defect taking place with an estimated rate of 1 in 37 cells entering mitosis (around 3\% of the mitoses, Figure S6).

Near-tetraploid cells were stable and did not revert to the near-diploid status, at least within the studied timeframe. They, however, grew at approximately $80 \%$ the proliferation rate of the near-diploid cells (Figure S5), possibly due to the extra time required to duplicate a much larger genome. A mathematical model of the proportion of near-diploid and neartetraploid cells in a mixed cell population, considering their different growth rates and the rate of spontaneous tetraploidization predicted that the proportion of near-tetraploid cells would stabilize at around $13 \%$ of the population (Figure S6). This prediction is in line with the proportion of cells with nuclei size above $3 \times$ de modal volume in the parental LS174T cell population (12.8\%, Figure S7).

In primary CRCs, strong somatic demethylation of SST1 is associated with TP53 mutations and LINE-1 demethylation (Figure 4F). The link between SST1 hypomethylation and spontaneous tetraploidization might explain its association with TP53 mutations, where the inactivation of TP53 would be necessary to evade tetraploidy-triggered cell cycle arrest $[53,67,84]$. While LS174 cells are TP53 wild-type, they harbor a homozygous frameshift mutation in $B A X$ and also in other pro-apoptotic genes. $B A X$ is a common MSI target because it contains a mutational hotspot $(G)_{8}$ mononucleotide tract in its coding sequence $[85,86]$. The inactivation of $B A X$ facilitates the survival of tetraploid cells at least as efficiently as the p53 or p21 knockouts [87]. Our experiments indicate that upon tetraploidization, LS174T cells activated the G2M checkpoint genes (Figure S10), but nevertheless, they continued to proliferate and did not enter apoptosis or cell cycle arrest.

Our findings are summarized in the model presented in Figure 5. In this model, SST1 demethylation takes place in a globally demethylated genome, resulting in an increased probability of spontaneous tetraploidization that in turn triggers p38-p53-p21-mediated cell cycle arrest. Therefore, cells that undergo tetraploidization would require the impairment of 
the p38-p53-p21 pathway either by mutations in TP53 (in MSS tumors) or by inactivation of essential downstream effectors such as $B A X$ (in MSI tumors) to evade cell cycle arrest $[67,84]$.

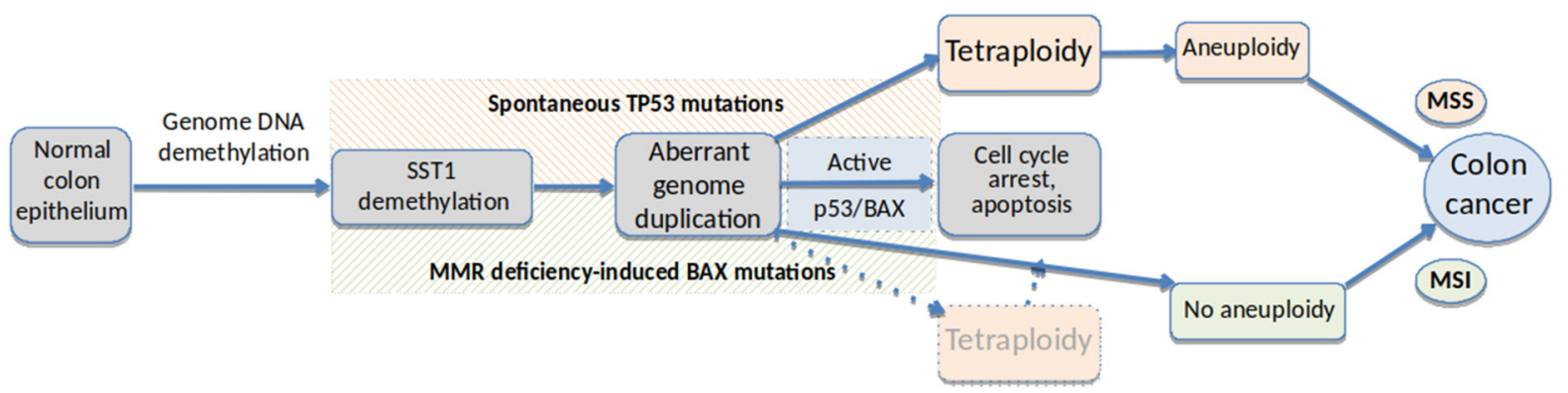

Figure 5. Model for a link between SST1 somatic demethylation, tetraploidy and TP53 and BAX mutations in CRC. In a genomic background of somatic DNA demethylation, strong demethylation of SST1 pericentromeric elements leads to genome duplication and consequent tetraploidy in CRC precursor cells. When cell cycle arrest or apoptosis networks are functional, the resultant tetraploid cells do not proliferate. When TP53 mutations in MSS CRC spontaneously occur before or during the presumably gradual demethylation of these (or other) sequences, the tetraploid cells survive initiating a pathway for aneuploidy and eventually CRC. In a less frequent MSI pathway for CRC, the tetraploid cells can evade apoptosis if there are somatic mutations in BAX and/or other pro-apoptotic proteins. In MSI CRC, the SST1 demethylation-associated tetraploidy is not essential for tumor progression, and the MSI mutator phenotype may lead to a pseudo-diploid tumor.

The cause of drastic SST1 demethylation in some tumors remains to be elucidated. Strong SST1 somatic demethylation was associated with high levels of LINE-1 hypomethylation in primary CRCs (Figure 4F), suggesting some common underlying mechanisms. This association was also observed in LS174T cells that exhibited much lower methylation in both SST1 and LINE-1 elements compared to DLD1 and HCT116 (Figure S7). However, there were fundamental differences in the hypomethylation affecting SST1 and LINE-1 sequences: While SST1 methylation in tumor samples mainly reflected the methylation of their matching normal tissue, LINE-1 elements were generally somatically hypomethylated in tumors (Figure 4). Therefore, the events that lead to strong demethylation in SST1 elements, while they may occur in a genetic background of global genomic demethylation, likely represent a different mechanism. We do not consider mutant p53 to directly underlie the strong demethylation of SST1 elements because the spectrum of TP53 mutations in the cases with strong demethylation is not atypical, with common single point mutations in typical codons (Figure S13). In this context, we previously reported that the demethylation of SST1 was associated with the downregulation of HELLS, a protein that has been denominated the epigenetic guardian of the repetitive elements [42].

A limitation of our study is that, due to their repetitive nature, we could not determine the precise chromosomal location of the SST1 elements that undergo somatic demethylation. We cannot rule out that demethylation of some of these elements, but no others, might have different phenotypic effects. Of note, LS174T subclones did not show gross alterations of any of the acrocentric chromosomes, where SST1 elements are mainly located, regardless of their average SST1 methylation level or ploidy. Preliminary analysis by CGH arrays of a small subset of CRCs with strong SST1 demethylation did not reveal a higher incidence of alterations in acrocentric chromosomes. Thus, we have no evidence for a regional effect caused by SST1 demethylation in CRC. In line with this observation, lymphocytes from ICF patients, which also exhibit hypomethylation of SST1 elements [38], do not typically show structural alterations on the acrocentric chromosomes [88]. ICF cells are deficient for DNMT3B, leading to the extensive hypomethylation of repetitive elements other than STT1, i.e., LINE-1, Alu, Sat2, Sat3 and Yhq, aberrant decondensation of centromere-adjacent heterochromatin and structural alterations in chromosomes 1, 16 and sometimes 9 [30,88]. Still, tetraploidization is not typical of ICF cells perhaps because, unlike CRCs with strong SST1 demethylation, ICF cells are p38-p53-p21-competent. 
The mechanisms linking SST1 demethylation with whole genome duplication also remain unresolved. The absence of structural alterations on the acrocentric chromosomes in LS174T cells suggests that regional chromatin decondensation does not play a major role. We recently reported that the demethylation of SST1 was associated with the expression of $T N B L$, a long non-coding RNA originating from these sequences and stable throughout the mitotic cycle, that formed a perinucleolar aggregate with RNA-binding proteins [43]. The function of this IncRNA, or its putative effect on genome duplication fidelity is still unknown. While SST1 demethylation could be linked to whole genome-doubling through a hypothetical negative effect on the cell cycle control, it is also plausible that it is not per se the direct cause of tetraploidization but a surrogate marker for the underlying epigenetic defect that leads to the genetic alteration.

Unfortunately, we cannot compare the data from our cohort with that of publicly available cohorts where whole-genome-doubling has been inferred [56], for instance, the TCGA COAD and READ datasets, because those samples have not been analyzed for SST1 methylation. The HM450K methylation arrays employed to profile methylation on TCGA samples do not cover these repetitive elements. Thus, the validation of our results has to be performed by analyzing additional fresh samples. SNP array or point-mutation-based methods that can infer tetraploid lineage in mixed cell populations may return definitive evidence $[61,89]$.

Despite these limitations, this report provides important clues relative to the role of somatic DNA demethylation in human cancer. The hypothesized causal relationship between the demethylation of SST1 pericentromeric repetitive elements and genome duplication observed in LS174T cells is supported by its association with mutational inactivation of p53 or pro-apoptotic proteins in a subset of human primary CRCs. The correlation between global demethylation and copy number alterations has been reported by us and many other researchers $[27,34,90]$. There is also solid mechanistic evidence for the oncogenic effect of genome-wide demethylation in CRC cell lines, as well as in mice, in which the DNA methyltransferases (DNMTs) have been genetically disrupted [31,33,91]. Lastly, the association between LINE-1 hypomethylation and hyperploidy has been described in ovarian cancers [92]. However, to our knowledge, we present the first evidence linking naturally occurring DNA demethylation in human CRC cells with the onset of tetraploidy, putatively involved in the early steps of tumorigenesis in a subset of CRCs $[52,93]$.

\section{Conclusions}

LS174T cells undergo spontaneous tetraploidization in vitro, associated with demethylation of SST1 repetitive elements. To the best of our knowledge, this is the first evidence linking naturally occurring DNA demethylation in human CRC cells with the onset of tetraploidy, which is likely involved in the early steps of tumorigenesis.

SST1 methylation in primary tumors reflects, in general, the methylation found in their matched normal tissues. SST1 demethylation occurs in around $17 \%$ of colorectal tumors ( $12 \%$ with moderate demethylation and $5 \%$ with strong demethylation), associated with mutations in TP53.

Supplementary Materials: The following are available online at https:/ /www.mdpi.com/article/ 10.3390/cancers13215353/s1, Figure S1: LINE-1 MS-QPCR, Figure S2: SST1 MS-QPCR vs. Bisulfite sequencing, Figure S3: LS174T nuclei size distribution, Figure S4: Genomic content of LS174T and derived clones measured by flow cytometry, Figure S5: Growth rate of LS174T and derived clones, Figure S6: Modeling the tetraploidization of LS174T cells, Figure S7: SST1 methylation and nuclei size in CRC MSI cell lines, Figure S8: Karyotype of OV-90 ovarian cancer cells, Figure S9: Transcriptional profiling of near-diploid and near-tetraploid LS174T clones, Figure S10: Gene Set Enrichment Analysis of the transcriptional profile of near-tetraploid LS174T clones, Figure S11: SST1 and LINE-1 $\triangle$ RDL vs. global methylation levels, Figure S12: Association of SST1 $\Delta$ RDL with clinicopathological and mutational characteristics of CRCs, Figure S13: TP53 mutations in SST1 demethylated cases, STR: STR analyses of all cell lines and derived clones analyzed in this study (zip-compressed), Table S1: clinical and molecular data of the 148 CRCs analyzed in this study 
(zip-compressed), Table S2: normalized and $\log 2$ transformed gene expression values of tetraploid vs diploid LS174T measured with Affymetrix ClariomTM S arrays including a chip-file with the probe to gene information required for the GSEA analysis (zip-compressed), GSEA: results of the GSEA analysis in HTML (zip-compressed).

Author Contributions: S.M.J. and S.A. set up the LINE-1 MS-QPCR technique and applied it to analyze the primary colorectal cancers. B.G. and M.N.-J. set up the SST1 MS-QPCR technique, generated the LS174T clones and performed all the analyses in LS174T clones and primary colorectal tumors. M.J.A.-D.G. and B.G. performed the analysis of the ovarian cancer cells. S.A. performed the statistical analyses and the transcriptome and HM450K analyses. I.G. led the karyotyping analysis. S.A., M.P. and B.G. designed the experimental strategy. S.A. and B.G. supervised the work. B.G., M.N.-J., M.P. and S.A. interpreted the results and wrote the manuscript. All authors have read and agreed to the published version of the manuscript.

Funding: This work has been supported by a grant to MP and SA from the Instituto de Salud Carlos III (FIS PI18/01484), Spanish Ministry of Science, Innovation and Universities, FEDER.

Institutional Review Board Statement: The study was conducted according to the guidelines of the Declaration of Helsinki, and approved by the Sanford-Burnham-Prebys (SBP) Medical Discovery Institute. Additional approval was obtained from the IRB of the IGTP to further analyze DNA samples of the study (approval code PI-18-252, 14 December 2018).

Informed Consent Statement: Informed consent was obtained and managed by the CHTN at the time of sample collection, following US regulations and the guidelines of the Declaration of Helsinki [64]. Patient data has been anonymized by the CHTN before submission to our laboratory and once again in our laboratory before publication. Thus, patient codes shown in this manuscript do not allow back-tracing the CHTN samples nor original donors.

Data Availability Statement: All data is included in the manuscript as Supplementary Materials. Original cell lines are publicly available at ATCC. Derived clones from our collection are available upon request. Tissue samples were provided by the Cooperative Human Tissue Network (CHTN), which is funded by the National Cancer Institute. Other investigators may have received specimens from the same subjects.

Acknowledgments: We thank M.A. Fernández Sanmartín and G. Requena Fernández from the IGTP Cytometry Unit for their support and advice on the FCM experiments. Microarrays studies were performed in the Microarrays Unit of Josep Carreras Leukaemia Research Institute. We are indebted to all members of the Cytogenetics Platform, Hematology Department at Germans Trias i Pujol Hospital, Catalan Institute of Oncology, Josep Carreras Leukaemia Research Institute (Badalona, Spain) for providing the karyotype studies and images.

Conflicts of Interest: The authors declare no conflict of interest.

\begin{abstract}
Abbreviations
CGH: comparative genome hybridization; CIN: chromosomal instability; CRC, colorectal cancer; $\mathrm{CV}$, coefficient of variation ( $\mathrm{CV}=\sigma / \mu$, where $\sigma$ is the standard deviation and $\mu$ the mean); DAPI, 4',6-diamidino-2-phenylindole; DNMT, DNA methyltransferase; FCM, flow cytometry; ICF, immunodeficiency, centromeric instability and facial anomalies syndrome; LINE-1, long interspersed nuclear element 1; MMR: DNA mismatch repair; MS-QPCR: methylation-sensitive quantitative PCR; MSI, microsatellite instability; MSS: microsatellite stability; RDL, relative demethylation ratio, i.e., the ratio between unmethylated vs. methylated or unmethylated vs. methylation-independent amplifiable molecules relative to a normalizing sample; STR: short tandem repeat; $\triangle$ RDL, differential relative demethylation ratio, also termed somatic demethylation, i.e., the difference of RDL between tumor and matching normal samples.
\end{abstract}

\title{
References
}

1. Symer, D.E.; Connelly, C.; Szak, S.T.; Caputo, E.M.; Cost, G.; Parmigiani, G.; Boeke, J.D. Human 11 retrotransposition is associated with genetic instability in vivo. Cell 2002, 110, 327-338. [CrossRef]

2. Kazazian, H.H., Jr.; Goodier, J.L. LINE drive. Retrotransposition and genome instability. Cell 2002, 110, 277-280. [CrossRef] 
3. Ehrlich, M.; Gama-Sosa, M.A.; Huang, L.-H.; Midgett, R.M.; Kuo, K.C.; McCune, R.A.; Gehrke, C. Amount and distribution of 5-methylcytosine in human DNA from different types of tissues or cells. Nucleic Acids Res. 1982, 10, 2709-2721. [CrossRef]

4. Bird, A. DNA methylation patterns and epigenetic memory. Genes Dev. 2002, 16, 6-21. [CrossRef] [PubMed]

5. Bogdanović, O.; Lister, R. DNA methylation and the preservation of cell identity. Curr. Opin. Genet. Dev. 2017, 46, 9-14. [CrossRef] [PubMed]

6. Heyn, H.; Li, N.; Ferreira, H.; Moran, S.; Pisano, D.; Gomez, A.; Diez, J.; Sanchez-Mut, J.V.; Setien, F.; Carmona, F.J.; et al. Distinct DNA methylomes of newborns and centenarians. Proc. Natl. Acad. Sci. USA 2012, 109, 10522-10527. [CrossRef]

7. Klutstein, M.; Nejman, D.; Greenfield, R.; Cedar, H. DNA methylation in cancer and aging. Cancer Res. 2016, 76, 3446-3450. [CrossRef] [PubMed]

8. Hoal-van Helden, E.G.; van Helden, P.D. Age-related methylation changes in DNA may reflect the proliferative potential of organs. Mutat. Res. 1989, 219, 263-266. [CrossRef]

9. Horvath, S.; Raj, K. DNA methylation-based biomarkers and the epigenetic clock theory of ageing. Nat. Rev. Genet. 2018, 19, 371-384. [CrossRef]

10. Martin, E.M.; Fry, R.C. Environmental influences on the epigenome: Exposure-associated DNA methylation in human populations. Annu. Rev. Public Health 2018, 39, 309-333. [CrossRef]

11. Sobhani, I.; Rotkopf, H.; Khazaie, K. Bacteria-related changes in host DNA methylation and the risk for CRC. Gut Microbes 2020, 12, 1800898. [CrossRef]

12. Berdasco, M.; Esteller, M. Aberrant epigenetic landscape in cancer: How cellular identity goes awry. Dev. Cell 2010, 19, 698-711. [CrossRef]

13. Feinberg, A.P.; Tycko, B. The history of cancer epigenetics. Nat. Rev. Cancer 2004, 4, 143-153. [CrossRef] [PubMed]

14. Baylin, S.B.; Jones, P.A. A decade of exploring the cancer epigenome-Biological and translational implications. Nat. Rev. Cancer 2011, 11, 726-734. [CrossRef]

15. Frigola, J.; Song, J.; Stirzaker, C.; Hinshelwood, R.A.; Peinado, M.A.; Clark, S. Epigenetic remodeling in colorectal cancer results in coordinate gene suppression across an entire chromosome band. Nat. Genet. 2006, 38, 540-549. [CrossRef] [PubMed]

16. Mayor, R.; Casadomé, L.; Azuara, D.; Moreno, V.; Clark, S.J.; Capellà, G.; Peinado, M.A. Long-range epigenetic silencing at 2q14.2 affects most human colorectal cancers and may have application as a non-invasive biomarker of disease. Br. J. Cancer 2009, 100, 1534-1539. [CrossRef] [PubMed]

17. Achinger-Kawecka, J.; Taberlay, P.C.; Clark, S.J. Alterations in three-dimensional organization of the cancer genome and epigenome. Cold Spring Harb. Symp. Quant. Biol. 2016, 81, 41-51. [CrossRef] [PubMed]

18. Bert, S.A.; Robinson, M.D.; Strbenac, D.; Statham, A.L.; Song, J.Z.; Hulf, T.; Sutherland, R.L.; Coolen, M.W.; Stirzaker, C.; Clark, S.J Regional activation of the cancer genome by long-range epigenetic remodeling. Cancer Cell 2013, 23, 9-22. [CrossRef] [PubMed]

19. Berman, B.P.; Weisenberger, D.J.; Aman, J.F.; Hinoue, T.; Ramjan, Z.; Liu, Y.; Noushmehr, H.; Lange, C.P.E.; van Dijk, C.M.; Tollenaar, R.A.E.M.; et al. Regions of focal DNA hypermethylation and long-range hypomethylation in colorectal cancer coincide with nuclear lamina-associated domains. Nat. Genet. 2011, 44, 40-46. [CrossRef] [PubMed]

20. Timp, W.; Bravo, H.C.; McDonald, O.G.; Goggins, M.; Umbricht, C.; Zeiger, M.; Feinberg, A.P.; Irizarry, R.A. Large hypomethylated blocks as a universal defining epigenetic alteration in human solid tumors. Genome Med. 2014, 6, 61. [CrossRef]

21. Du, Q.; Bert, S.A.; Armstrong, N.J.; Caldon, C.E.; Song, J.Z.; Nair, S.S.; Gould, C.M.; Luu, P.L.; Peters, T.; Khoury, A.; et al. Replication timing and epigenome remodelling are associated with the nature of chromosomal rearrangements in cancer. Nat. Commun. 2019, 10, 1-15. [CrossRef] [PubMed]

22. Toyota, M.; Ahuja, N.; Ohe-Toyota, M.; Herman, J.G.; Baylin, S.B.; Issa, J.-P. CpG island methylator phenotype in colorectal cancer. Proc. Natl. Acad. Sci. USA 1999, 96, 8681-8686. [CrossRef] [PubMed]

23. Fang, M.; Ou, J.; Hutchinson, L.; Green, M.R. The BRAF oncoprotein functions through the transcriptional repressor MAFG to mediate the CpG island methylator phenotype. Mol. Cell 2014, 55, 904-915. [CrossRef] [PubMed]

24. Fang, M.; Hutchinson, L.; Deng, A.; Green, M.R. Common BRAF(V600E)-directed pathway mediates widespread epigenetic silencing in colorectal cancer and melanoma. Proc. Natl. Acad. Sci. USA 2016, 113, 1250-1255. [CrossRef] [PubMed]

25. Serra, R.W.; Fang, M.; Park, S.M.; Hutchinson, L.; Green, M.R. A KRAS-directed transcriptional silencing pathway that mediates the CpG island methylator phenotype. eLife 2014, 3, e2313. [CrossRef]

26. Ehrlich, M. DNA methylation in cancer: Too much, but also too little. Oncogene 2002, 21, 5400-5413. [CrossRef] [PubMed]

27. Ehrlich, M. DNA hypomethylation in cancer cells. Epigenomics 2009, 1, 239-259. [CrossRef]

28. Beisel, C.; Paro, R. Silencing chromatin: Comparing modes and mechanisms. Nat. Rev. Genet. 2011, 12, 123-135. [CrossRef]

29. Yang, A.S.; Estecio, M.; Doshi, K.; Kondo, Y.; Tajara, E.H.; Issa, J.-P. A simple method for estimating global DNA methylation using bisulfite PCR of repetitive DNA elements. Nucleic Acids Res. 2004, 32, e38. [CrossRef] [PubMed]

30. Weisenberger, D.J.; Campan, M.; Long, T.I.; Kim, M.; Woods, C.; Fiala, E.; Ehrlich, M.; Laird, P.W. Analysis of repetitive element DNA methylation by MethyLight. Nucleic Acids Res. 2005, 33, 6823-6836. [CrossRef] [PubMed]

31. Eden, A.; Gaudet, F.; Waghmare, A.; Jaenisch, R. Chromosomal instability and tumors promoted by DNA hypomethylation. Science 2003, 300, 455. [CrossRef] [PubMed]

32. Esteller, M. Epigenetics in cancer. N. Engl. J. Med. 2008, 358, 1148-1159. [CrossRef]

33. Gaudet, F.; Hodgson, J.G.; Eden, A.; Jackson-Grusby, L.; Dausman, J.; Gray, J.W.; Leonhardt, H.; Jaenisch, R. Induction of tumors in mice by genomic hypomethylation. Science 2003, 300, 489-492. [CrossRef] [PubMed] 
34. Suzuki, K.; Suzuki, I.; Leodolter, A.; Alonso, S.; Horiuchi, S.; Yamashita, K.; Perucho, M. Global DNA demethylation in gastrointestinal cancer is age dependent and precedes genomic damage. Cancer Cell 2006, 9, 199-207. [CrossRef]

35. Samuelsson, J.K.; Dumbovic, G.; Polo, C.; Moreta, C.; Alibés, A.; Ruiz-Larroya, T.; Giménez-Bonafé, P.; Alonso, S.; Forcales, S.-V.; Perucho, M. Helicase lymphoid-specific enzyme contributes to the maintenance of methylation of SST1 pericentromeric repeats that are frequently demethylated in colon cancer and associate with genomic damage. Epigenomes 2016, 1, 2. [CrossRef] [PubMed]

36. Thoraval, D.; Asakawa, J.-I.; Wimmer, K.; Kuick, R.; Lamb, B.; Richardson, B.; Ambros, P.; Glover, T.; Hanash, S. Demethylation of repetitive DNA sequences in neuroblastoma. Genes Chromosom. Cancer 1996, 17, 234-244. [CrossRef]

37. Nishiyama, R.; Qi, L.; Tsumagari, K.; Weissbecker, K.; Dubeau, L.; Champagne, M.; Sikka, S.; Nagai, H.; Ehrlich, M. A DNA repeat, NBL2, is hypermethylated in some cancers but hypomethylated in others. Cancer Biol. Ther. 2005, 4, 446-454. [CrossRef]

38. Kondo, T.; Bobek, M.P.; Kuick, R.; Lamb, B.; Zhu, X.; Narayan, A.; Bourc'his, D.; Viegas-Péquignot, E.; Ehrlich, M.; Hanash, S.M. Whole-genome methylation scan in ICF syndrome: Hypomethylation of non-satellite DNA repeats D4Z4 and NBL2. Hum. Mol. Genet. 2000, 9, 597-604. [CrossRef]

39. Hansen, R.S.; Wijmenga, C.; Luo, P.; Stanek, A.M.; Canfield, T.K.; Weemaes, C.M.; Gartler, S.M. The DNMT3B DNA methyltransferase gene is mutated in the ICF immunodeficiency syndrome. Proc. Natl. Acad. Sci. USA 1999, 96, 14412-14417. [CrossRef]

40. Xu, G.-L.; Bestor, T.H.; Bourc'his, D.; Hsieh, C.-L.; Tommerup, N.; Bugge, M.; Hulten, M.; Qu, X.; Russo, J.J.; Viegas-Péquignot, E. Chromosome instability and immunodeficiency syndrome caused by mutations in a DNA methyltransferase gene. Nature 1999, 402, 187-191. [CrossRef] [PubMed]

41. Epstein, N.D.; Karlsson, S.; O’Brien, S.; Modi, W.; Moulton, A.; Nienhuis, A.W. A new moderately repetitive DNA sequence family of novel organization. Nucleic Acids Res. 1987, 15, 2327-2341. [CrossRef] [PubMed]

42. Huang, J.; Fan, T.; Yan, Q.; Zhu, H.; Fox, S.; Issaq, H.J.; Best, L.; Gangi, L.; Munroe, D.; Muegge, K. Lsh, an epigenetic guardian of repetitive elements. Nucleic Acids Res. 2004, 32, 5019-5028. [CrossRef]

43. Dumbovic, G.; Biayna, J.; Banús, J.; Samuelsson, J.; Roth, A.; Diederichs, S.; Alonso, S.; Buschbeck, M.; Perucho, M.; Forcales, S.-V. A novel long non-coding RNA from NBL2 pericentromeric macrosatellite forms a perinucleolar aggregate structure in colon cancer. Nucleic Acids Res. 2018, 46, 5504-5524. [CrossRef] [PubMed]

44. Dumbović, G.; Sanjuan, X.; Perucho, M.; Forcales, S.-V. Stimulated emission depletion (STED) super resolution imaging of RNAand protein-containing domains in fixed cells. Methods 2021, 187, 68-76. [CrossRef] [PubMed]

45. Holland, A.J.; Cleveland, D.W. Boveri revisited: Chromosomal instability, aneuploidy and tumorigenesis. Nat. Rev. Mol. Cell Biol. 2009, 10, 478-487. [CrossRef] [PubMed]

46. Boveri, T. Concerning the origin of malignant tumours by Theodor Boveri. Translated and annotated by Henry Harris. J. Cell Sci. 2008, 121, 1-84. [CrossRef]

47. Yamamoto, T.; Rabinowitz, Z.; Sachs, L. Identification of the chromosomes that control malignancy. Nat. New Biol. 1973, 243, 247-250. [CrossRef] [PubMed]

48. Sansregret, L.; Swanton, C. The role of aneuploidy in cancer evolution. Cold Spring Harb. Perspect. Med. 2017, 7, a028373. [CrossRef]

49. Ben-David, U.; Amon, A. Context is everything: Aneuploidy in cancer. Nat. Rev. Genet. 2020, 21, 44-62. [CrossRef]

50. Barr, F.A.; Gruneberg, U. Cytokinesis: Placing and making the final cut. Cell 2007, 131, 847-860. [CrossRef] [PubMed]

51. Paim, L.M.G.; Fitzharris, G. Tetraploidy causes chromosomal instability in acentriolar mouse embryos. Nat. Commun. 2019, 10, 4834. [CrossRef] [PubMed]

52. Margolis, R.L. Tetraploidy and tumor development. Cancer Cell 2005, 8, 353-354. [CrossRef]

53. Fujiwara, T.; Bandi, M.; Nitta, M.; Ivanova, E.V.; Bronson, R.T.; Pellman, D. Cytokinesis failure generating tetraploids promotes tumorigenesis in p53-null cells. Nature 2005, 437, 1043-1047. [CrossRef]

54. Davoli, T.; de Lange, T. Telomere-driven tetraploidization occurs in human cells undergoing crisis and promotes transformation of mouse cells. Cancer Cell 2012, 21, 765-776. [CrossRef] [PubMed]

55. Zack, T.I.; Schumacher, S.E.; Carter, S.L.; Cherniack, A.D.; Saksena, G.; Tabak, B.; Lawrence, M.S.; Zhang, C.-Z.; Wala, J.; Mermel, C.H.; et al. Pan-cancer patterns of somatic copy number alteration. Nat. Genet. 2013, 45, 1134-1140. [CrossRef] [PubMed]

56. Dewhurst, S.M.; McGranahan, N.; Burrell, R.A.; Rowan, A.J.; Gronroos, E.; Endesfelder, D.; Joshi, T.; Mouradov, D.; Gibbs, P.; Ward, R.; et al. Tolerance of whole-genome doubling propagates chromosomal instability and accelerates cancer genome evolution. Cancer Discov. 2014, 4, 175-185. [CrossRef]

57. Kuznetsova, A.Y.; Seget, K.; Moeller, G.K.; de Pagter, M.S.; Roos, J.A.; Dürrbaum, M.; Kuffer, C.; Müller, S.; Zaman, G.J.R.; Kloosterman, W.P.; et al. Chromosomal instability, tolerance of mitotic errors and multidrug resistance are promoted by tetraploidization in human cells. Cell Cycle 2015, 14, 2810-2820. [CrossRef] [PubMed]

58. Samuelsson, J.K.; Alonso, S.; Yamamoto, F.; Perucho, M. DNA fingerprinting techniques for the analysis of genetic and epigenetic alterations in colorectal cancer. Mutat. Res. Mol. Mech. Mutagen. 2010, 693, 61-76. [CrossRef]

59. Lucito, R.; Healy, J.; Alexander, J.; Reiner, A.; Esposito, D.; Chi, M.; Rodgers, L.; Brady, A.; Sebat, J.; Troge, J.; et al. Representational oligonucleotide microarray analysis: A high-resolution method to detect genome copy number variation. Genome Res. 2003, 13, 2291-2305. [CrossRef] [PubMed]

60. Oostlander, A.; Meijer, G.; Ylstra, B. Microarray-based comparative genomic hybridization and its applications in human genetics. Clin. Genet. 2004, 66, 488-495. [CrossRef] [PubMed] 
61. Rasmussen, M.; Sundström, M.; Göransson Kultima, H.; Botling, J.; Micke, P.; Birgisson, H.; Glimelius, B.; Isaksson, A. Allelespecific copy number analysis of tumor samples with aneuploidy and tumor heterogeneity. Genome Biol. 2011, 12, R108. [CrossRef]

62. Feber, A.; Guilhamon, P.; Lechner, M.; Fenton, T.; Wilson, G.A.; Thirlwell, C.; Morris, T.J.; Flanagan, A.M.; Teschendorff, A.E.; Kelly, J.D.; et al. Using high-density DNA methylation arrays to profile copy number alterations. Genome Biol. 2014, 15, R30. [CrossRef]

63. Lane, D.P. P53, guardian of the genome. Nature 1992, 358, 15-16. [CrossRef] [PubMed]

64. Hollstein, M.; Sidransky, D.; Vogelstein, B.; Harris, C.C. P53 mutations in human cancers. Science 1991, 253, 49-53. [CrossRef] [PubMed]

65. Burrell, R.A.; McClelland, S.E.; Endesfelder, D.; Groth, P.; Weller, M.-C.; Shaikh, N.; Domingo, E.; Kanu, N.; Dewhurst, S.M.; Gronroos, E.; et al. Replication stress links structural and numerical cancer chromosomal instability. Nature 2013, 494, 492-496. [CrossRef] [PubMed]

66. McGranahan, N.; Favero, F.; de Bruin, E.C.; Birkbak, N.; Szallasi, Z.; Swanton, C. Clonal status of actionable driver events and the timing of mutational processes in cancer evolution. Sci. Transl. Med. 2015, 7, 283ra54. [CrossRef] [PubMed]

67. Andreassen, P.R.; Lohez, O.D.; Lacroix, F.B.; Margolis, R.L. Tetraploid state induces p53-dependent arrest of nontransformed mammalian cells in G1. Mol. Biol. Cell 2001, 12, 1315-1328. [CrossRef] [PubMed]

68. World Medical Association. World Medical Association Declaration of Helsinki. Ethical principles for medical research involving human subjects. Bull. World Health Organ. 2001, 79, 373-374.

69. Robin, T.; Capes-Davis, A.; Bairoch, A. CLASTR: The Cellosaurus STR similarity search tool—A precious help for cell line authentication. Int. J. Cancer 2020, 146, 1299-1306. [CrossRef] [PubMed]

70. Davis, J.M. Animal Cell Culture: Essential Methods; Wiley: Hoboken, NJ, USA, 2011; ISBN 9780470666586.

71. Baranovskaya, S.; Soto, J.L.; Perucho, M.; Malkhosyan, S.R. Functional significance of concomitant inactivation of hMLH1 and hMSH6 in tumor cells of the microsatellite mutator phenotype. Proc. Natl. Acad. Sci. USA 2001, 98, 15107-15112. [CrossRef] [PubMed]

72. Schneider, C.A.; Rasband, W.S.; Eliceiri, K.W. NIH image to ImageJ: 25 years of image analysis. Nat. Methods 2012, 9, 671-675. [CrossRef] [PubMed]

73. Bergkessel, M.; Guthrie, C. Colony PCR. Methods Enzymol. 2013, 529, 299-309. [CrossRef] [PubMed]

74. Alonso, S.; González, B.; Ruiz-Larroya, T.; Domínguez, M.D.; Kato, T.; Matsunaga, A.; Suzuki, K.; Strongin, A.Y.; GimenezBonafe, P.; Perucho, M. Epigenetic inactivation of the extracellular matrix metallopeptidase ADAMTS19 gene and the metastatic spread in colorectal cancer. Clin. Epigenetics 2015, 7, 124. [CrossRef] [PubMed]

75. Assenov, Y.; Müller, F.; Lutsik, P.; Walter, J.; Lengauer, T.; Bock, C. Comprehensive analysis of DNA methylation data with RnBeads. Nat. Methods 2014, 11, 1138-1140. [CrossRef]

76. Pidsley, R.; Wong, C.C.Y.; Volta, M.; Lunnon, K.; Mill, J.; Schalkwyk, L.C. A data-driven approach to preprocessing illumina 450K methylation array data. BMC Genom. 2013, 14, 293. [CrossRef] [PubMed]

77. Subramanian, A.; Tamayo, P.; Mootha, V.K.; Mukherjee, S.; Ebert, B.L.; Gillette, M.A.; Paulovich, A.; Pomeroy, S.L.; Golub, T.R.; Lander, E.S.; et al. Gene set enrichment analysis: A knowledge-based approach for interpreting genome-wide expression profiles. Proc. Natl. Acad. Sci. USA 2005, 102, 15545-15550. [CrossRef] [PubMed]

78. R Core Team. R: A Language and Environment for Statistical Computing; R Foundation for Statistical Computing: Vienna, Austria, 2019.

79. Feltz, C.J.; Miller, G.E. An asymptotic test for the equality of coefficients of variation from K populations. Stat. Med. 1996, 15, 646-658. [CrossRef]

80. Mouradov, D.; Sloggett, C.; Jorissen, R.N.; Love, C.G.; Li, S.; Burgess, A.W.; Arango, D.; Strausberg, R.L.; Buchanan, D.; Wormald, S.; et al. Colorectal cancer cell lines are representative models of the main molecular subtypes of primary cancer. Cancer Res. 2014, 74, 3238-3247. [CrossRef] [PubMed]

81. Tom, B.H.; Rutzky, L.P.; Jakstys, M.M.; Oyasu, R.; Kaye, C.I.; Kahan, B.D. Human colonic adenocarcinoma cells. I. Establishment and description of a new line. In Vitro 1976, 12, 180-191. [CrossRef]

82. Provencher, D.M.; Lounis, H.; Champoux, L.; Tétrault, M.; Manderson, E.N.; Wang, J.C.; Eydoux, P.; Savoie, R.; Tonin, P.N.; Mes-Masson, A.M. Characterization of four novel epithelial ovarian cancer cell lines. In Vitro Cell. Dev. Biol. Anim. 2000, 36, 357-361. [CrossRef]

83. Ren, B.; Cam, H.; Takahashi, Y.; Volkert, T.; Terragni, J.; Young, R.A.; Dynlacht, B.D. E2F integrates cell cycle progression with DNA repair, replication, and G2/M checkpoints. Genes Dev. 2002, 16, 245-256. [CrossRef] [PubMed]

84. Aylon, Y.; Oren, M. P53: Guardian of ploidy. Mol. Oncol. 2011, 5, 315-323. [CrossRef] [PubMed]

85. Rampino, N.; Yamamoto, H.; Ionov, Y.; Li, Y.; Sawai, H.; Reed, J.C.; Perucho, M. Somatic frameshift mutations in the BAX gene in colon cancers of the microsatellite mutator phenotype. Science 1997, 275, 967-969. [CrossRef]

86. Woerner, S.M.; Benner, A.; Sutter, C.; Schiller, M.; Yuan, Y.P.; Keller, G.; Bork, P.; Doeberitz, M.V.K.; Gebert, J.F.; Yuan, Y. Pathogenesis of DNA repair-deficient cancers: A statistical meta-analysis of putative real common target genes. Oncogene 2003, 22, 2226-2235. [CrossRef]

87. Castedo, M.; Coquelle, A.; Vivet, S.; Vitale, I.; Kauffmann, A.; Dessen, P.; Pequignot, M.O.; Casares, N.; Valent, A.; Mouhamad, S.; et al. Apoptosis regulation in tetraploid cancer cells. EMBO J. 2006, 25, 2584-2595. [CrossRef] 
88. Ehrlich, M.; Sanchez, C.; Shao, C.; Nishiyama, R.; Kehrl, J.; Kuick, R.; Kubota, T.; Hanash, S.M. ICF, an immunodeficiency syndrome: DNA methyltransferase 3B involvement, chromosome anomalies, and gene dysregulation. Autoimmunity 2008, 41, 253-271. [CrossRef]

89. Carter, S.L.; Cibulskis, K.; Helman, E.; McKenna, A.; Shen, H.; Zack, T.; Laird, P.W.; Onofrio, R.C.; Winckler, W.; Weir, B.A.; et al. Absolute quantification of somatic DNA alterations in human cancer. Nat. Biotechnol. 2012, 30, 413-421. [CrossRef]

90. Rodriguez, J.; Frigola, J.; Vendrell, E.; Risques, R.-A.; Fraga, M.; Morales, C.; Moreno, V.; Esteller, M.; Capella, G.; Ribas, M.; et al. Chromosomal instability correlates with genome-wide DNA demethylation in human primary colorectal cancers. Cancer Res. 2006, 66, 8462-9468. [CrossRef] [PubMed]

91. Karpf, A.R.; Matsui, S.-I. Genetic disruption of cytosine DNA methyltransferase enzymes induces chromosomal instability in human cancer cells. Cancer Res. 2005, 65, 8635-8639. [CrossRef]

92. Zeimet, A.G.; Fiegl, H.; Goebel, G.; Kopp, F.; Allasia, C.; Reimer, D.; Steppan, I.; Mueller-Holzner, E.; Ehrlich, M.; Marth, C. DNA ploidy, nuclear size, proliferation index and DNA-hypomethylation in ovarian cancer. Gynecol. Oncol. 2011, 121, 24-31. [CrossRef]

93. Storchova, Z.; Kuffer, C. The consequences of tetraploidy and aneuploidy. J. Cell Sci. 2008, 121, 3859-3866. [CrossRef] [PubMed] 